NOTE TO USERS

This reproduction is the best copy available. 



\section{Architecture of Expressiveness and Communication Technology: Studying the Skin}

\section{Alexsandra Wendzich, B.Arch}

A thesis submitted to the Faculty of Graduate Studies and Research in Partial fulfillment of the requirements for the degree of Master of Architecture (M.ARCH) Professional 
Library and Archives

Canada

Published Heritage

Branch

395 Wellington Street Ottawa ON K1A ON4 Canada
Bibliotheque et

Archives Canada

Direction du

Patrimoine de l'édition

395 , rue Wellington

Ottawa ON K1A ON4

Canada
Your file Votre référence

ISBN: 978-0-494-71538-3

Our file Notre réfárence

ISBN: $978-0-494-71538-3$
NOTICE:

The author has granted a nonexclusive license allowing Library and Archives Canada to reproduce, publish, archive, preserve, conserve, communicate to the public by telecommunication or on the Internet, loan, distribute and sell theses worldwide, for commercial or noncommercial purposes, in microform, paper, electronic and/or any other formats.

The author retains copyright ownership and moral rights in this thesis. Neither the thesis nor substantial extracts from it may be printed or otherwise reproduced without the author's permission.
AVIS:

L'auteur a accordé une licence non exclusive permettant à la Bibliothèque et Archives Canada de reproduire, publier, archiver, sauvegarder, conserver, transmettre au public par télécommunication ou par l'Internet, prêter, distribuer et vendre des thèses partout dans le monde, à des fins commerciales ou autres, sur support microforme, papier, électronique et/ou autres formats.

L'auteur conserve la propriété du droit d'auteur et des droits moraux qui protège cette thèse. $\mathrm{Ni}$ la thèse ni des extraits substantiels de celle-ci ne doivent être imprimés ou autrement reproduits sans son autorisation.
In compliance with the Canadian Privacy Act some supporting forms may have been removed from this thesis.

While these forms may be included in the document page count, their removal does not represent any loss of content from the thesis.
Conformément à la loi canadienne sur la protection de la vie privée, quelques formulaires secondaires ont été enlevés de cette thèse.

Bien que ces formulaires aient inclus dans la pagination, il n'y aura aucun contenu manquant. 


\begin{abstract}
As a large portion of the world becomes accustomed to using Communication Technology as a means of dialogue in both public and private life, it is important to see the effects that this technology has on the social relationships of people to specific spaces, on a global bases and on a more intimate level. As the consumption and necessity for information rises, it is important to see how the availability of information affects the way we navigate within electrical and physical spaces, and whether or not it is possible to integrate Communication Technology into physical spaces.

The objective of this thesis is to identify the global, local and intimate changes that are arising as a result of the increased use of Communication Technology; to find a way at which we begin to inform Architecture using the ever-increasing complexity of Communication Technologies; to create a gateway to Carleton University that reflects the interests of dwellers and visitors, to make the artifact and the ritual more meaningful. The thesis explores methods of skin manipulation in Architecture to find a way in which to relate the non-material nature of information into the material nature of the skin.
\end{abstract}

This thesis examines how the manipulation of skin in Architecture may be explored to create a bond between Communication Technology and Architecture. Programmatically, the design for an O-Train gate-way to Carleton University is undertaken in order to create a bond between dwellers and visitors to the University. 


\section{Acknowledgments}

I would like to offer my sincerest of gratitude to my parents, who have been a beacon of light when there was none, family, siblings, especially to Tess, who has become a great inspiration, and finally, friends who supported me through this experience. I would also like to greatly honor my thesis advisor, Greg Andonian, who shared with me his wisdom and knowledge, giving me the courage to successfully acknowledge my full potential. It has been a great privilege to experience this process with all of you.

This thesis is dedicated in loving memory of my dear cousin Alwyn Rottschäfer 17.02.1975 - 10.09.2010. You will remain in my heart forever my love. 


\section{Table of Contents}

$\begin{array}{lc}\text { Abstract } & \text { ii } \\ \text { Acknowledgments } & \text { iii } \\ \text { Table of Contents } & \text { iv } \\ \text { List of Figures } & \text { vi } \\ \text { Introduction } & 1\end{array}$

Part One: Communication and Cultural Values

Chapter One: Macrocosmic Level (World)

1.1 Movement of Information in Supermodernity 4

1.2 Ethnocide 8

1.3 Value of Information 12

Chapter Two: Microcosmic Level (City and Body)

2.1 Transportation and Communication: 15

The removal of the body from the city 18

2.2 Defining Place through Communication Technology 18

$\begin{array}{ll}2.3 \text { In-Betweennes } & 19 \\ & 20\end{array}$

2.4 Memory in Place (owners of Place) 20

Part Two: Architecture as Skin

Chapter Three: Skin Manipulation 30

3.1 Defining Skin 32

Chapter Four: Skin as Expression

4.1 Architects 35

4.1.1 Jean Nouvel $\quad 35$

4.1.2 Toyo Ito 38

4.2 Christian Moeller $\quad 42$

-Communication Technologies relationship with skin

Chapter Five: Methodology of Skin Manipulation

5.1 Criteria for Evaluation $\quad 49$

5.2 Immaterial Material 50

5.3 Analyzing Architectural methods 51

5.3.1 Site $\quad 52$

5.3.2 Function of the Facility 53

5.3.3 Public and Privacy 55 
Part Three: The Design of Gateway to Carleton University

Chapter Six: Site

6.1 Critique of the existing O-train shelter

59

6.2 Program and Spatial Requirements

61

Conclusion

Glossary

83

Bibliography

86 


\section{List of Figures}

Figure 1. Saadiyat Island Development

Philip Jordidio, AE Architecture in the Emirates. Published by Taschen, 2007.

Figure 2. Jewish Museum Berlin (Site). .26

Bernard Scheider, Daniel Liebskind Jewish Museum Berlin: Between the Lines. Prestel Verlag, 1999.

Figure 3. Jewish Museum Berlin.

Bernard Schneider, Daniel Liebskind Jewish Museum Berlin: Between the Lines. Prestel Verlag, 1999.

Figure 4. Jean Nouvel Arab Institute

Conway Lloyd Morgan, Jean Nouvel: The elements of Architecture.

Universe Publishing, 1998

Figure 5. Agbar Tower (Jean Nouvel)

arcspace.com -web resource

www.europ-cities.com/.../22090_agbar_tower

Figure 6. Euralille Development (Nouvel)

-Conway Lloyd Morgan, Jean Nouvel: The elements of Architecture.

Universe Publishing, 1998

Figure 7. Mediatech (Toyo Ito).

Toyo Ito, Image of Architecture in electronic age.

Copyright 2000-2010, Designboom - Web Resource

Figure 8. Bitwall 2 (Christian Moeller)

-Christian Moeller, A Time And Place-Media Architecture.

Lars Muller Publishers, 2004

Figure 9. Nosy ( Christian Moeller). .46

Christian Moeller, A Time And Place-Media Architecture.

Lars Muller Publishers, 2004

Figure 10. Kinetic Light Sculpture (Christian Moeller).

-Christian Moeller, A Time And Place-Media Architecture.

Lars Muller Publishers, 2004

Figure 11. Tower of Wind (Toyo Ito). www.arc1.uniroma1.it/saggio/conferenze/10/4d.htm.

www.detaildesignonline.com/factfile/1245 
Figure 12. O-Train Site Image by Author

Figure 13. Campus Avenue Image by Author

Figure 14. Images of Transportation System Image by Author

Figure 15. Site Plan of Carleton University. Carleton University

Figure 16: Site Plans. Carleton University

Figure 17: Image of Site. 68 Image by Author

Figure 18: First Floor Plan 69 Image by Author

Figure 19: Second Floor Plan 70 Image by Author

Figure 20: Third Floor Plan .71 Image by Author

Figure 21: Fourth Floor Plan. Image by Author

Figure 22: Roof Plan .73 Image by Author

Figure 23: Basement and Tunnel Plan 74 Image by Author

Figure 24: Sections 75 Image by Author

Figure 25: Section .76 Image by Author

Figure 26: Elevations. .77 Image by Author

Figure 27 \& 28: Facade. 


\section{Introduction}

Dating to the invention of the telegraph-which enables people to communicate across great distances from different locales around the world- the advent of communication technologies has gone as far as one's imagination can extend. As millions of radio signals travel across the globe to their respective destinations each day, communication technologies have allowed us to share our experiences and cultures wherever these linkages exist. ${ }^{1}$ Carolyn A. Lin

Communication Technology (CT) has played a significant role in people's lives. It has progressed in such a short time that it seems that we have absorbed it without realizing its effects. CT began with letter writing, transported by trains, then advanced to the telegraph, telephones, and rapidly transitioned to wireless devices, such as the internet and cellular phones. At present, it seems that some people cannot even function efficiently without it. As a large portion of the world becomes accustomed to using $\mathrm{CT}$ as a means of communicating in both public and private life, the specified technology affects humanity, the way we navigate through spaces, communicate, interact, and live. As a result, Architecture has also been influenced by this change since it is part of the narrative that human beings have created from their ways of navigating within this world.

\section{Line of Argumentation}

In order to demonstrate CT's effects on humanity, the author will first explore it on a global scale (macrocosmic). The following questions are poised: How does communication influence culture and trends concerning information as a commodity due to media implications? To this end, Supermodernity, Ethnocide

\footnotetext{
${ }^{1}$ Carolyn A. Lin, "Introduction," in Communication Technology and Social Change: Theory and Implications, Carolyn A. Lin and David J. Atkin, eds. 3 (Lawrence Erlbaum Associates, Inc. 2007).
} 
and the value of information are discussed. Second, the exploration of CT on a city/individual scale (microcosmic) is undertaken, examining how communication devices create a fusion between the work place and home, and how the relationships of private and public life merge.

Third, before demonstrating how CT has influenced Architecture, the connection between the individual and collective memory, and Architecture will be explored. Fourth, in order to demonstrate how CT has influenced Architecture, buildings "skins" will be examined. Skin is a first mode of communication between the visitor and Architecture. The importance of the skin in Architecture will not only be studied as a means of introduction to a building, but also as a mediator between the visitor and the inhabitants. Fifth, the author introduces specific case studies from three architects exemplifying the importance of skin manipulation in order to connect to site and site conditions, as well as CT's influence in Architecture.

Sixth, before the design portion of the thesis is broached, potential methods of skin manipulation are examined. Thus, how CT can be connected to site using skin as a medium. Expressiveness of the skin in Architecture is under investigation, to find a way in which to relate the non-material nature of information to the material nature of the skin. Lastly, the design portion of the thesis is discussed, how the ever-increasing CT may become an important signifier in creating a gateway to Carleton University that defines the interests of dwellers and visitors to make the artifact and ritual more meaningful. Programmatically, the design for an O-Train gateway to Carleton University is 
perused in order to create a bond between the inhabitants (students) and the visitors to the university. 


\section{Part One: Communication and Cultural Values}

\section{Chapter One: Macrocosmic Level (World)}

In this section, Communication Technology (CT) will be examined on a global scale. The cultural impact of CT will be broached by asking the following question: Is the overabundance of information being seen as a commodity? Supermodernity will also be examined to clarify the aforementioned question and to determine whether value in information is being diminished due to the accessibility of mobile technological devices. As CT becomes readily available to most of the world's population, does it severely impact culture? In order to determine whether more powerful cultures have the ability through media technology to impose their norms upon other cultures, and whether this is causing a "Global Culture," the theory of Ethnocide will be examined.

\subsection{Movement of Information in Supermodernity}

Prior to the implementation of $\mathrm{CT}$, information traveled as fast as a matter of months, weeks or even days, depending on whether it was carried on land by locomotives or over sea, by ships. The emergence of the steam engine by James Watt in 1765 allowed for a broader range of travel. This range of travel made it easier and faster to access different cultures and building materials, thus permitting these materials and styles to be interchanged between countries more quickly. The steam engine began the first mode of communication transport, allowing information to be distributed throughout the country at a faster rate. It was not until 1835 that Samuel Morse invented the first successful electromagnetic telegraph system that could withstand long distance 
communication. This mode of communication permitted information to be distributed within seconds of the message being relayed. According to Neil Postman:

Prior to the telegraph, information could be moved only as fast as a train could travel: about thirty five miles per hour. Prior to the telegraph, information was sought as part of the process of understanding and solving particular problems. Prior to the telegraph, information tended to be local interest... it removed space as an inevitable constraint on the movement of information, and for the first time, transportation and communication were disengaged from each other...the telegraph made information into a commodity, a 'thing' that could be bought and sold irrespective of its issues or meaning. ${ }^{2}$

Since then, Communication Technology has progressed in such a way that information has become readily available to the public, through the World Wide Web and through cellular devices. Statistics collected from the United States Census bureau on internet usage suggests a global increase of internet use from December 31, 2000 to September 30, 2009 by $25.6 \%$, bringing the world use from $360,985,492$ to $1,733,993,741$. According to the data collected during this time, the largest amount of internet application is occupied by North America with an increase of $74.2 \% .^{3}$ With information being received and delivered within seconds of being produced, we may begin to ask whether the overabundance of information is allowing for a more significant spread of knowledge at a faster pace, or whether accessing that information has simply become a commodity.

\footnotetext{
${ }^{2}$ Neil Postman, Technopoly: The Surrender of Culture to Technology (New York :Vintage Books, 1992), 6768.

${ }^{3}$ Miniwatts World Total internet Marketing Group, "US Census Bureau, Internet World Stats," www.newwebsitebuilders.net/Astounding\%internet\%20world\%stats $\% 20$ and $\% 20$ online $\% 20$ growth. $\% 20$ expo sure.pdf. (accessed June 21, 2010).
} 
To explain the latter more efficiently, the subject of commodity will be discussed using quantifiable spaces, such as transient spaces, that tie closely to the functionality of Communication Technology. When a traveler steps into any transient space like an airport, railway station or platform, he is confronted with being in a quantifiable relationship with his surroundings with the lack of qualifiable interaction that is to be expressed in their environment. ${ }^{4}$ It is important to distinguish what differentiates qualifiable space and quantifiable space. While qualifiable space maintains its relationship to the environment, history and inhabitants, a quantifiable space deals with functionality. A visitor to the space (the traveler) encounters numerical quantifiable communication systems, telling him where to go, what time and how to get there. The communication systems indicate how people can orient themselves within the space efficiently.

Like the transient spaces of travel, mobile technologies also create a distance between the traveler and their surroundings. Neil Postman's Technopoly: The Surrender of Culture to Technology explores communication systems and their cultural impacts. According to Postman, prior to the onset of rapid communication systems such as the telegraph, the information divulged was based solely for a more intimate local network. ${ }^{5}$ As the speed in which information could be transmitted increased, information became a commodity, stripped of its value in meaning and disclosure. Information could be accessed quickly by anyone who wanted to have it.

\footnotetext{
${ }^{4}$ Quantifiable space is the ability to produce numerical information without divulging anything about what the space inhabits.

${ }^{5}$ Postman, 67-68.
} 
The overabundance and accessibility of information taken out of context from historical identity caused an excess of meaningful events, which Marc Augé coined as "Supermodernity". It is this notion of Supermodernity that begins to compress time, taking meaningful historical events and creating them as an excess of meaningful events. The term Supermodernity, also known synonymously as hypermodernity, differs from modernity in such a way that its venture is to intensify the ability to have freedom and individual choice while using reason and knowledge. Since time is rapidly moving within the realm of Supermodernity, history cannot be used as a resourceful guide within it. The latter intensifies its value using technology to gain freedom from the past.

Modernity, used in sociological terms, looks to past events in history as a teleological guideline on how to appropriate the future, in economics, politics and standards of living. Modernism improves the social surroundings by considering the past and not reinventing its mistakes: "Modernity is thus a particular kind of time consciousness which defines the present in its relation to the past, which must be consciously recreated..." ${ }^{6}$

Marc Augé writes, "Supermodernity causes a number of excesses. Time moves so quickly that it is difficult to get one's bearings in history. Distance is so easily surmounted that one loses the sense that territoriality and space have any reality, and the individual becomes the point of reference for the distribution of information." ${ }^{7}$ This collapse in time creates a compression of information; when remote distances and places are accessible through travel and communication

${ }^{6}$ Gerard Delanty, Blackwell Encyclopaedia of Sociology, 2007 "Modernity."

${ }^{7}$ Marc Augé, Non-Places Introduction to an Anthropology of Supermodernity (New York: Verso, 1995), 30 
devices, Supermodernity "compresses space" in such a way that we can live and communicate in the comfort of our homes. ${ }^{8}$ While in a space of Supermodernity the traveler relates to the space individually, only through quantifiable means, such as date of birth, name, address; the individual is categorised with a numerical value while in the space of Supermoderity. The collapse of time in the world of Supermoderity removes people from historical events. Furthermore, this collapse flattens time to the present, by a reflection through media, written documents and images.

Since Supermodernity seems to distinguish CT as a series of events that promote individuality non-relational to the past, how does this mode of communication impact the various cultures that are bound to the relationship with history and customs, both on an individual and global level?

\subsection{Ethnocide}

The overabundance of information traveling around the globe through Internet, media and cellular activity, seems to be causing a generalized global culture in which Tony Fry, author of Design Futuring - Sustainability, Ethics and New Practice, denotes as Ethnocide.

Ethnocide occurs when a more powerful culture imposes upon another its norms and practices. Media seems to be one of the more powerful uses of CT that expresses a means towards a Global Culture as it imposes images and commercials as a series of choices to individuals. According to Fry,

\footnotetext{
${ }^{8}$ Augé.
} 
Not withstanding 'ethnic roots' it seems that increasingly people choose 'their' culture from the options of what to believe in (or not), what to wear, eat, where to shop, where to live, what music to listen to, movies to watch, what friends to hang out with, what politics to be aligned with, what technology to make a sign of the self, or what designer products to purchase. Culture everywhere, is for sale. ${ }^{9}$

Fry acknowledges that the basis for Global Culture seems to be created from the information available; however, he is not saying that this new mode of attaining information is going to change religious or traditional thinking. Rather, he is saying that a new kind of culture is being manifested alongside traditional culture; a culture that dictates itself as consumerism. This statement of course should not be used as generalized means to appropriate that all cultures are being influenced by media, as not all parts of the world have access to communication systems that make the dispersion of generalized media-related information possible. For the clarification of this argument, the statement that media creates a Global Culture through Ethnocide will not be applicable to any indigenous cultures.

The evidence of the infiltration of Ethnocide is expressed loudly through methods of Architectural expression throughout the globe as well. The event that seems to make this possible is the ability to transpose Architectural ideas by CT via the internet. The possibility to move information at a faster rate permits various Architectural firms around the globe to compete for a chance to initiate their designs in various countries around the world. The immediate flow of information permits architects to stay connected with the building process without

\footnotetext{
${ }^{9}$ Tony Fry, Design Futuring - Sustainability, Ethics and New Practice (Berg Editorial Office, 2009), 116.
} 
leaving their office, by sending electronically new drafts of architectural drawings, specs and important information within seconds of it being requested. Inherently, the ability to move information long distances within seconds makes it more economically feasible for an Architecture firm to transpose their design guidelines to a site without displacing themselves from the comfort of their office setting. The infiltration of information technologies into the practice of Architecture imposes different methods of building design, material usage and expression of values. Dubai is a place that exemplifies the introduction of various forms of Architecture from around the globe to ameliorate its expression as an important business and entertainment centre. An Architectural collage of structures of world scale is being developed on the island of Saadiyat off the coasts of Abu Dhabi, Dubai, Doha and many other cities. The island of Saadiyat development is scheduled to be finished by 2012 . The island will boast the works of Zaha Hadid from London Studios, Frank Gehry from Los Angeles, and Jean Nouvel from Paris studios, just to name a few. The purpose of naming the aforementioned architects is to concretise the argument that a variety of Architectural firms around the globe are being implemented into Saadiyat's development plan. The diversity of architecture firms taking part in the Dubai development is substantial. The architecture firms taking part in the project come from China, Japan, United States, United Arab Emirates, Germany, United Kingdom, France, the Netherlands and Uruguay. 


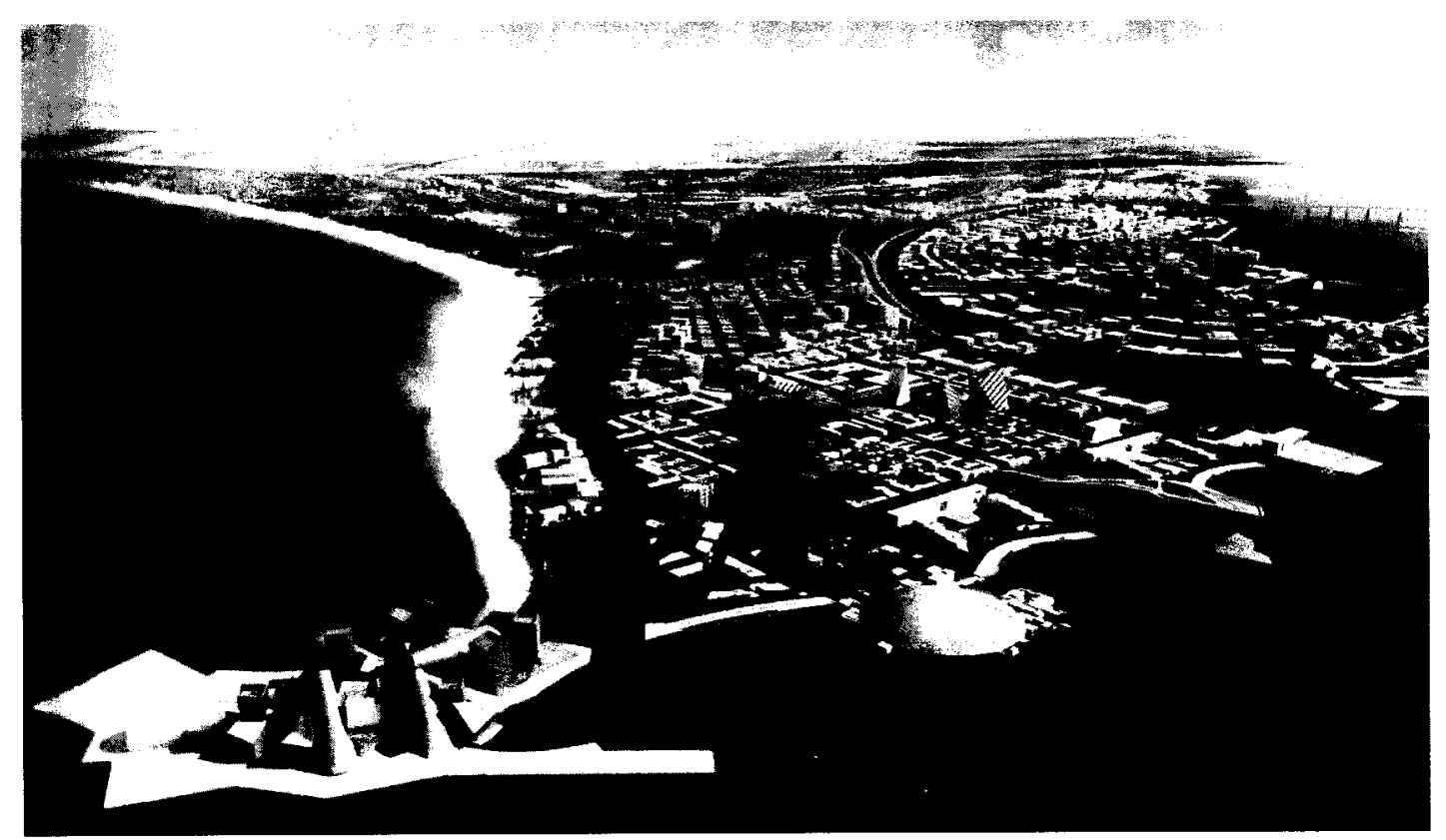

\section{Figure 1. Saadiyat Island Development}

This figure shows the development proposal for the Saadiyat Island off the coast of Abu Dhabi. The project is scheduled to be completed in 2012 . On the coast of the Island from left to right are the proposals from Gehry, Ito and Hadid.

As Dubai invites different firms to express themselves Architecturally within its borders, it is moving further away from being able to define its cultural origins. Consequently, a global affiliation is being fabricated, thus creating a place that promotes global identity.

The ready movement of information seems to impose a set of norms upon various societies, telling us how to dress, what to eat and where to entertain ourselves. This movement imposes a sense of familiarity around the globe from one city to the next, thus setting the trend that CT seems to be creating a global cultural identity. 


\subsection{Value of Information}

Technological innovation in communication systems, such as mobile phones, internet or various other communication devices, requires a mode of transportation for information in what Derrick De Kerckhove coined as being "the E-Principle."10 The E-Principle establishes itself as the prime mover for information using electricity as its new text. One of the primary uses for CT is the ability for parties to communicate faster and more efficiently with one another. The new text, "Electricity," permits the user of the technology to pass an infinite amount of information to another destination in the same time it takes to press "Enter". The immediate flow of information almost eliminates our way to connect at a physical level since information can be shared, stored and played back at any moment. In this respect information begins to create a new relationship with space and the sender and receiver of information. Although some forms of communication systems allow for easier access to information, they begin to create problems; communication systems seem to form a larger gap in the area of misconceptions of the information conveyed. For example, when sending any information through the internet of cellular devices, there is always the possibility that the receiver may not understand, or take another position on what information the sender is trying to convey. The text is an example of a quantitative approach to conversing. When receiving the text, the receiver may not fully understand the emotional meaning behind the message; the information

\footnotetext{
${ }^{10}$ Derrick De Kerckhove, The Architecture of Intelligence (Berlin: Birkhauser-Publishers for Architecture, 2001), 22.
} 
sent will bring forward a different significance or outcome depending on how it is written.

As information becomes more accessible due to $\mathrm{CT}$, does this accessibility demonstrate that the information communicated is perceived at its truest value or being seen as a commodity?

In Neil Postman's book, he argues that the abuses of technology within a cultural setting affect human perception. It seems as though by making information readily available to the reader, which he describes using the telegraph, the information loses its value, as it can be bought or sold irrespective of its dialogue within. By the transmission of information through electricity, that which would have been available only in magazines or books brought by transport information lost its ability to be seen as something culturally bound. By relying on the plentiful bombardment of information, could this be a prelude to a dependence upon information as "truth" to function in society?

Postman answers this question by relaying a series of facts to random people; he proclaims that this information is scientifically credible. What the study conveys is that people tend to believe everything that is supported factually, even fictitiously, by scientific studies. It seems that people tend to believe everything they read or hear if it appears to come from a credible source such as magazines, news articles and media related information. Now that CT is available to unaccredited sources through "web pages" via the internet, the movement of unresolved information can flow readily whether the facts are true or false. Postman states, "In the middle ages, people believed in the authority of 
their religion, no matter what. Today, we believe in the authority of science, no matter what."11 Presently, information on the internet may be subject to being seen as truth.

${ }^{11}$ Postman, 58. 


\section{Chapter Two: Microcosmic Level (City and Body)}

This section of the thesis discusses the impacts of CT on a more intimate level, that of the city and the individual. The first section will examine the potential for communication devices to create a fusion between the work place and home, and how this may potentially create confusion between what it means to be in private and public life. The second part of this chapter discusses what it means to be in Place and how Communication Technology seems to act as a transitory space where another world and identity can be broached; the state of being in "In-betweenness".

\subsection{Transportation and Communication: The Removal of the Body from the City}

The introduction of improved transportation systems in and out of the city permitted a new growth of community outside of the city limits, known as suburbia. This infrastructure of living provided a more affordable advantage for the citizens to live outside of the city limits, while being able to commute to work every day. This method of living introduced a separation of the home (private) and work place (public) and created a time frame that indicated when it was time to work and time for home.

A similar event has the potential to create the same effect that transportation has on the dislocation of home life from the city limits; this event is known as "The Global Village". Joseph Rykwert, author of The Seduction of Place: The City in the Twenty-First Century, offers a futurologists discussion about the potential for a lighter spread of population due to the advancement in 
CT and its ability to create a sense of freedom for the large city centers. The connection to communication devices will permit for work and leisurely related activities to progress without the need to physically move the body into proximity of the city:

The arrival of information technology and the consequent communications explosion of the conurbations would produce a much lighter-perhaps even continuous-low density population spread, which was named the global village. The global village of the futurologists' imaginings is, note it well, a village, not a town or city. Computerized workers would not need physical contact with each other or any controlling central organization, and would be able to operate from their homes, which would simply be dotted about the countryside. ${ }^{12}$

$\mathrm{CT}$, however, seems to be introducing a third dimension of living expectations, that which broaches the differentiation between work and home, creating a sense of "in-betweenness". The state of "in-betweenness" is a transitory state which blurres the recognition between the act of work and home.

The technological philosopher Derrick De Kerckhove introduces the notion that, "Wireless technologies change our relationships to physical space because they dilate and dilute human gatherings instead of bringing them together in one point." ${ }^{\text {13 }}$ Since modular technologies persuade for more individuality and freedom of interaction within space, it further enhances their position as being connected to Supermodernity through their inability to interact with public space.

That said, the act of work and home can be broached by removing the physical need for being in any space to perform tasks. Since many communication devices are mobile, they can be taken anywhere and used to

\footnotetext{
${ }^{12}$ Joseph Rykwert, The Seduction of Place: The City in the Twenty First Century (New York: Pantheon Books, 2000), 17-18.

${ }^{13}$ De Kerckhove, 27.
} 
perform work-related tasks in any space, such as in a vehicle, house, or park. Any space can become a work environment as long as the mobile connection to perform the appropriate tasks is available.

The cellular phone not only acts as an extension of our physical bodies but of our mental ones. It initiates connectivity to the world, allowing for the immediacy of information at the end of a finger tip. It possesses the information which can evoke a sense of power and awareness of events. Moreover, it can evoke a sense of security, knowing where we are at all times in relation to the world; it fills the airwaves with, "MY presence, at least my potential presence. ${ }^{14}$ This notion of connectivity implies a false sense of security, as it cannot protect us from harm but rather aid us in designing for ourselves a safer path to tread. The cell phone creates the e-nomad, one who surfs information and invades space:

Because it can be carried all the time, the cellular phone is the communication device closest to the body. It gives freedom of movements, allowing one to carry one's files, concerns, office, connections and d-bases on one's body. It is a direct extension of touch, vision and hearing, a probing and roaming device for worldwide navigation. ${ }^{15}$

The internet and associated mobile communication devices allow for the interconnecting with and absorbing of information without the need of being connected to physical space. The physical and electrical space must be taken as a duality of one another; one should not become dominant over the other. This duality will account for a new definition of what Place is to become and how CT and physical spaces can be intertwined. While the mode of CT does not remove the body from physical space, it enhances the mental affiliation to the

\footnotetext{
${ }^{14}$ De Kerckhove, 28

15 Ibid. 28.
} 
world through outgoing and incoming information. Due to this flow of information, a new interpretation of Place emerges.

\subsection{Defining Place through Communication Technology}

Since the implementation of mobile connectivity into the daily routine of the public, technology has evolved to serve as an implementation of being in Place. It seems that by having a continuous geographical awareness of where we are positioned at all times, it permits for a freedom to feel connected to Place without being in physical space. CT seems to be directly affiliated to the "here and now", while the physical place connects its relationship to historical relationships, involving memory. If $\mathrm{CT}$ is not affiliated to physical consecutiveness directly, then what function does the wide spread of connection have with Place?

The philosopher Kant defines Place as being directly affiliated to the physicality of the body, "The more we reflect on place, however, the more we recognize it to be something not merely characterizable but actually experienced in qualitative terms. These terms, for example, colour, texture and depth, are known to us only in and by the body that enters and occupies a given place... How can someone be in a place except through one's own body?" 16 According to Kant, place seems to only exist through one's inherent ability to be physically connected to place. If this definition of place is considered verifiable then what kind of connection does CT have to being in place?

Since CT is not directly connected with the experience of place through the body, the theorist Michael Certeau offers another theory of how the absence

${ }^{16}$ Edward S. Casey, The Fate of Place, A Philosophical History (California: University of California Press, 1998), 204. 
of these qualities would begin to define place, or rather "non place". When Michel de Certeau discusses the notion of "non-place", it can be noted that nonplace begins to exude negative qualities of place, essentially the absence of place from itself. For instance, if "non-places" was to be defined, it would have to be expressed as everything it is not: "If place can be defined as relational, historical and concerned with identity, then space which cannot be defined as relational, or historical, or concerned with identity will be a non-place."17

It seems that the theories of both Kant and Certeau are juxtaposed from one another. While Kant connects the body with the qualitative experience of place, Certeau states that the body in space of "non-places" does not connect qualifiably but rather quantifiably. If the body is to be removed from Place, can it still be possible for someone to experience Place as defined by Kant while not actually inhabiting physically in a Place? To answer this question we may look into how mobile CT has infiltrated and commanded the way we navigate within space.

\subsection{In-Betweenness}

CT seems to pivot between a point of being connected to Place and what Mark Augé in the last section called "non-place". While the communication device is an extension of the human body, the task that is being performed is not connected to site specificity or the physical world. Rather, CT seems to fit within the realm of "In-betweenness." In-betweenness is the state of being in a transitory space, that of a threshold or gateway between one state and the next. This state "In-

17. Marc Augé, Non-Places Introduction to an Anthropology of Supermodernity (New York: Verso, 1995), 7778 
betweenness" in relation to CT suggests that a person or subject is caught between two extreme-contrasting conditions; the state of being caught between physical and electrical worlds. For example, at the same time a subject is surfing the internet or conversing on a cellular device, he is conversing outside the realm of the physical relationship to space. In that moment the subject has removed themselves from being connected to a Place and is in a transitory state between being immersed in a relationship that has no reference to historical or site specificity. The body, however, remains immersed in space. In-betweeness, in the case of $\mathrm{CT}$, renders a subject between two planes of being, the physical space and electrical space. An example of "In-betweenness" lies in the realm of chat rooms and related sites specifically used for the act of conversing. When entering these sites the subject is stripped of his identities and social status, and is immersed in a transitional setting where a new identity can be formulated. When the subject has removed himself from the social interaction that the site provides, they can re-enter into the physical world without having changed status.

Up to this point the CT relationship to place has been broached using different states of connectivity. The next section will broach the interaction with place using memory as a signifier for connectivity.

\subsection{Memory in Place (owners of Place)}

When a person enters a building, they might be bombarded with questions concerning what the place represents, who it belongs to, and what value may be taken away from their experience in this particular place. Place embodies the 
connection to the inhabitant of the building through memory and history facilitated through the experiences and connection that the inhabitant has with place. According to Noeleen Murray, Nick Shepherd and Martin Hall:

Social Institutions are important repositories (subjects) of memories and also valuable 'albums' of broken instances, promising possibilities, and lived moments in the lives of those associated with them. As memory sites, social institutions have important stories to tell about the people linked to the facilities, their geographical and social location, and ways in which institutions in the modernizing city informed different aspects of their lives. ${ }^{18}$

There are many ways in which memory can be engaged. For the purpose of this section two contrasting elements of memory theory will be investigated. Paul Ricoeur's Memory History, Forgetting, discusses whether the ownership of memory can be recognized as collective or personal memory. The original and primordial character of personal memory ties to the use of ordinary language. According to Ricoeur, the term "self" refers to the notion, in remembering something one remembers oneself and "my memories are not yours." Memories of one person cannot be transferred to another, as this is a singular memory; "memories" are a private possession. To further understand what Ricoeur means by the word "memory" we must explore his interpretation of both Saint Augustine's and French philosopher Maurice Halbwachs' definitions of memory.

According to Paul Ricoeur, Saint Augustine approaches memory using 'personal memory' as his subjective. He states, "Memory is of the past, and this is that of my impressions; in this sense, this past is my past,... which allows us to

\footnotetext{
${ }^{18}$ Noeleen Murray, Nick Shepherd and Martin Hall, Desire Lines Space, Memory and Identity in the Post Apartheid City (London: Routledge, 2007), 145.

${ }_{19}$ Ricoeur, 96.
} 
move from the living present to past childhood. ${ }^{20}$ Associating memory as a personal entity permits an individual to have total control over the outcome of the memory. The way one encounters a place and experiences it will set forth the plane in which the memory will be perceived.

According to Ricoeur the theory of Maurice Halbwaches states that memory is collective in nature, "a collective entity, which he names group society." ${ }^{21}$ He disagrees with the idea of personal memory as discussed above, refuting that personal memory cannot exist without outside stimuli to initiate the act of remembering: "a person remembers only by situating himself within the viewpoint of one or several groups and one or several currents of collective thought...One does not remember alone."22 When immersed within a social setting the outside stimuli encountered become part of the process of memory making. If one is to come upon a similar setting or experience to the one that primarily collected the memory, it is possible for the recollection of that particular memory to be remembered.

Social institutions act as places for social and collective practices of memory through their ability to collect images and associate them to specific moments within the space. Through the interaction of public experiences within these spaces, the act of creating memory is more easily broached due to the overabundance of social interactions and images processed during the experience. Social institutions create memories within a geographical setting,

\footnotetext{
${ }^{20}$ Ricoeur, 96.

21 lbid, 120.

22 lbid, 121.
} 
placing them within a chronological time frame, which allows memory to implant itself within a historical construct.

Personal memory plays a significant role in how we begin to define ourselves on an emotional scale within space; the way one remembers does not necessarily reflect the way others remember the place, "a memory image is affective in nature-that is, it is sensorially derived and emotionally charged...Recollection is a re-enactment of experience, which involves...imagination and emotion."23

An example of a building that exemplifies the ability to connect history and memory is Daniel Libeskind's Jewish Museum in Berlin, completed in January 1999. His architecture demonstrates the significant connection of the historical Berlin through the integration of Jewish history with the city plan. The Museum is located on the intersection of Margrafenstrass and Lindenstrass in northern Friedrichstadt. The two parts of Friedrichstadt, until the demolition of the Berlin wall, were separated by the southern and northern sections of the same block. During the war the area was devastated considerably. The devastation provoked reconstruction of the urban area, which spanned many years and engendered various architectural typologies, leaving a collage of various building styles. Libeskind describes the site and his architectural relation to site as a "heterogeneous order" because of the large number of structural variations of architectural eras: "The entire location is marked by a congeries of unrelated structures from very different eras, of varying architectural styles and quality, and

\footnotetext{
${ }^{23}$ Giuliana Bruno, Public Intimacy, Architecture And the Visual Arts (Massachusetts: Massachusetts Institute of Technology, 2007), 22.
} 
reflecting diverse notions of urbanity." ${ }^{24}$ The problem that the museum faced was how to successfully develop the integration of all the different architectural qualities and assemble them together to create a unified design. To solve this problem Libeskind designed the museum in what would be described as a "new autonomous" view; Bernhard Schneider "argued for an autonomy from the Berlin Municipal Museum."25 The self-governed Architecture differentiates itself from the surrounding with materiality, height and structure. By creating an unrelational architecture to the surroundings, it was possible to infiltrate the meaning and values behind the reasoning for the structure, without specifically becoming involved with one aspect of its surroundings.

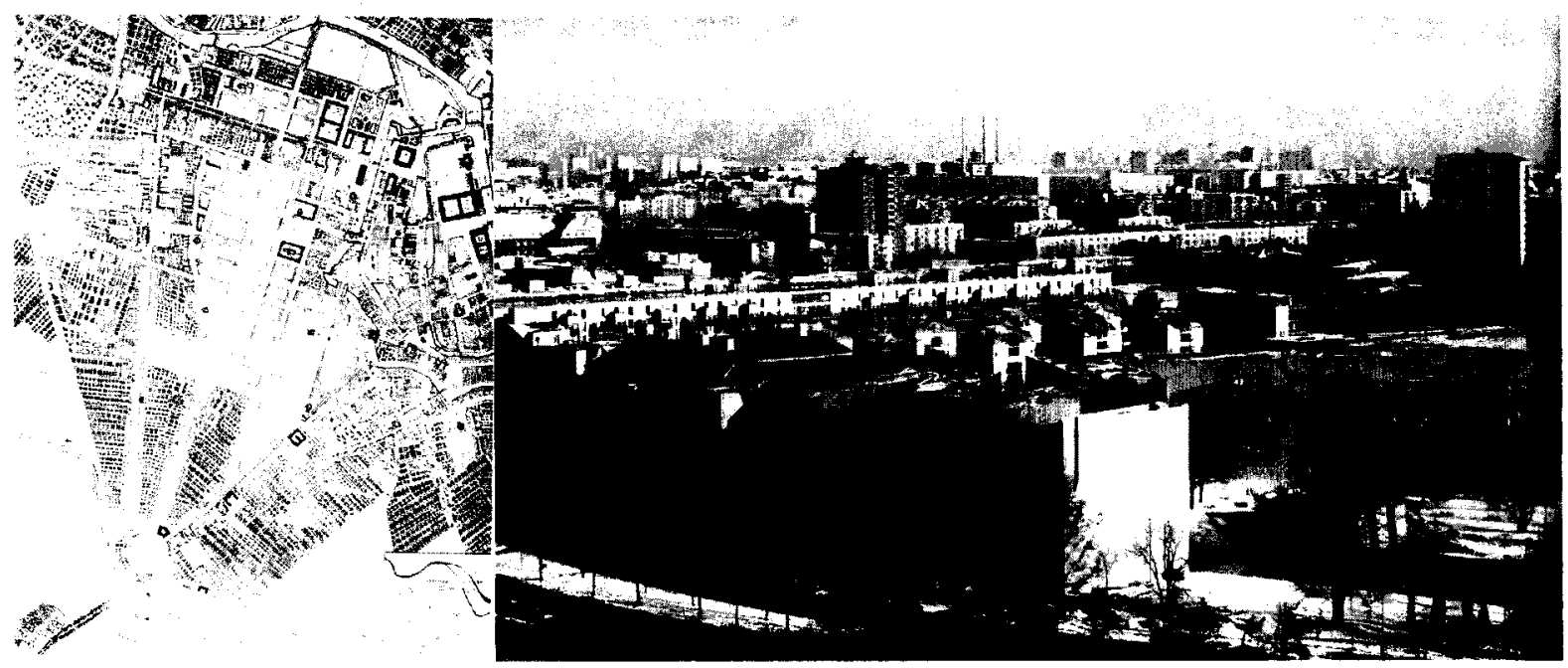

Figure 2. Jewish Museum Berlin (Site)

The right image shows the surrounding area and the differentiation in material to the Jewish Museum. The Left image is a map of the Friedrichstadt (site).

\footnotetext{
${ }^{24}$ Bernhard Schneider, Daniel Libeskind: Jewish Museum Berlin-Between The Lines (New York: Prestel Books, 2007), 27.

${ }^{25}$ Meera Dean, "Daniel Libeskind", http://wso.williams.edu/ mdeean/berlin/libeskind.html (accessed June 24, 2010).
} 
The irregularity of the museum's shape sets it apart from the existing museum.

Libeskind purposefully initiated the idea of a building wounded to illustrate the wounded history of the Holocaust, "The structure's shining silver façade will eventually patinate over time. Its slit windows are designed to suggest scratches, wounds and scars." ${ }^{26}$ The value of the architecture binds itself to the "social, political and Cultural history of the Jews in Berlin from the $4{ }^{\text {th }}$ Century to the present. ${ }^{27}$ Three main ideas underlined the building's design:

First, the impossibility of understanding the history of Berlin without understanding the enormous intellectual, economic and contribution made by the Jewish citizens of Berlin. Second, the necessity to integrate physically and spiritually the meaning of the Holocaust into the consciousness and memory of the city of Berlin. Third, that only through the acknowledgment and incorporation of this erasure and void of Jewish life in Berlin, can the history of Berlin and Europe have a human future. ${ }^{28}$

The museum's jagged shape derived from what Libeskind calls, "imaginary lines on the city map," ${ }^{29}$ which connect significant addresses of important people in Jewish history. The lines create a sense of no apparent beginning or end to the design, permitting a continuous fluidity throughout the building, defining the important spaces within the continuous body, "A recurrent basic motif of the design are long parallel or intersecting lines without beginning or end that define sharply pointed, dramatic bodies or spaces." 30

The dramatic bodies and spaces that Libeskind refers to are the three different symbolic routes that may be taken within the building; each route

\footnotetext{
${ }^{26}$ Mark Favermann, Berlins Jewish Museum By Daniel Libeskind: A Flawed Museum in a Deconstructionist Masterwork, (Berkshire Website Hosting),2009. www.berkshirefinearts.com/?page=article_id1112\&catlD=26

${ }^{27}$ Daniel Libeskind, Between The Lines.2010. www.daniel-libeskind.com (Accessed May $\overline{4}, 2010$ )

${ }^{28}$ Ibid

${ }^{29}$ Schneider, 36.

30 lbid, 36.
} 
symbolizes a unique experience of the Jewish Berlin peoples. Each of the experiential spaces accentuates an emotional response in connection to the history behind the space.

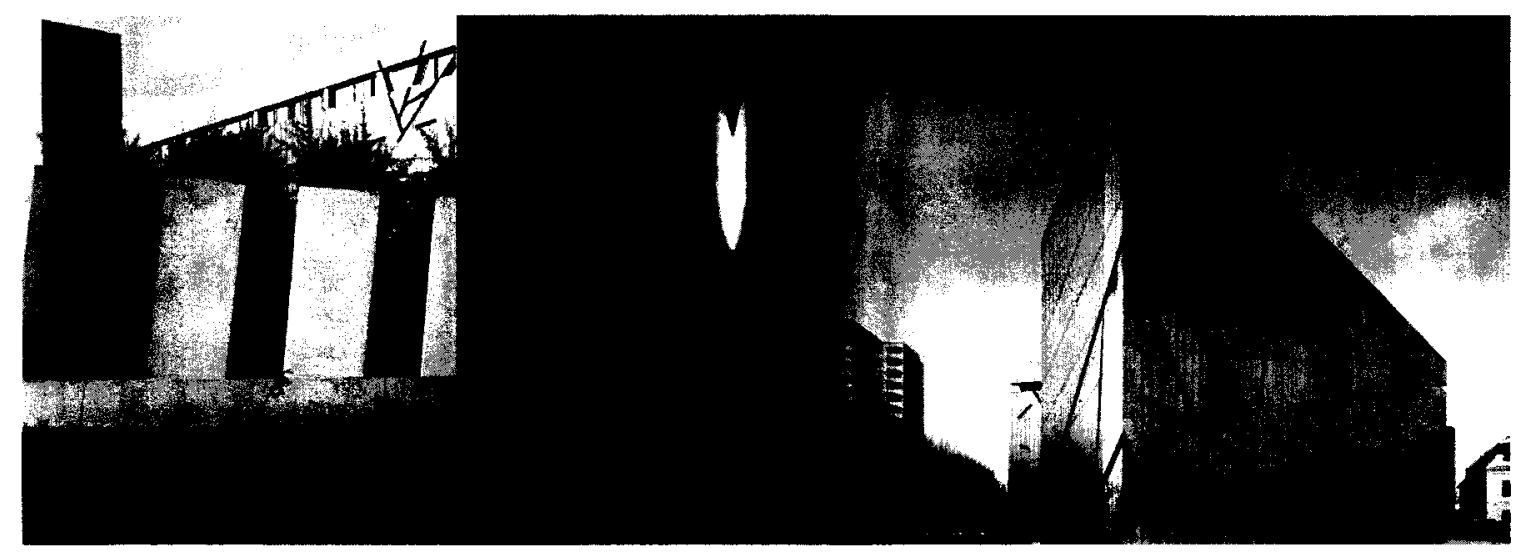

\section{Figure 3. Jewish Museum Berlin}

The figure shows from left to right the Garden of Exile and Emigration, Interior of Holocaust Void and the façade of the Museum. The latter shows the cut lines in the skin, which signifies the direct connection to the site.

The longest of the pathways, "Axis of Continuity," Continuity" which connects the old museum with the new. This pathway creates the main artery from which two other connections branch off, "The architect describes the Axis of Continuity as the continuation of Berlin's history." ${ }^{32}$

The second path, "Axis of Emigration," leads to the E.T.A Hoffman Garden exterior to the building. The main focal point within the garden is the forty-nine concrete columns which make up a planter for willow oak trees:

\footnotetext{
${ }^{31}$ Schneider, .40

${ }^{32}$ Ibid, 40
} 
The upside down garden (the Garden of Exile and Emigration presents a $7 \times 7$ tilted square. The columns contain earth and an underground irrigation system which permits willow oak to emerge and bind together at the top. Forty eight of these columns are filled with the earth of Berlin and stand for 1948-the formation of the State of Israel. The one central column contains the earth of Jerusalem and stands for Berlin itself. ${ }^{33}$

Because the garden tilts 12 degrees, it attempts to disorient the visitor by establishing a sense of instability among the towers. ${ }^{34}$ The disorientation within the space symbolizes the confusion and disorientation upon the removal of the Jewish population from Berlin, while the trees stand for hope and life, growing forth from the destruction of the Berlin soils.

The axis known as the "Axis of the Holocaust" leads to the space known as the "Holocaust Tower." This tower emphasizes a separation from the world by creating a void within one passageway of the subterranean floor wherein sound and light are dimly apparent. The separation from sound and light pulls the visitor back into their own body, heightening their other senses. The void is a barren, unheated space, which evokes in the visitor a heightening of the senses and as a result, creates an emotion connecting to the space through the senses; Philosopher Juhani Pallasmaa writes, "Architecture is the art of reconciliation between ourselves and the world, and this mediation takes place through the senses. ${ }^{35}$ The connection to the space can be best emphasized by the emotion response of "melancholia." To best understand the act of melancholia, we must broach Paul Ricoeur's Memory, History, Forgetting. Ricoeur discusses "Blocked

\footnotetext{
${ }^{33}$ Schneider, 40

${ }^{34}$ David Howes. "Architecture of The Senses". Sense of The City Exhibition Catalogue. Montreal, 2005. www.david-howes.com/DH-research-sampler-arch-senses.htm.

${ }^{35}$ Juhani Pallasmaa, The Eyes of The Skin: Architecture and the Senses (Great Britain: Wiley-Academy, 2005), 72.
} 
Memory" as the root for the wounded or the sick memory. This memory can be comprised of a traumatic experience, a wound or scar. The way in which an individual copes with a wound or scar is through mourning or melancholia. Mourning is the action that accompanies a traumatic experience or the loss of a loved one or of something that we hold dear. ${ }^{36}$ It is this process that accompanies the word work, "work of remembering," the one who is mourned no longer exists. Only when the courage to accept the trauma is demonstrated, can reconciliation be possible, "The work of mourning is the cost of the work of remembering, but the work of remembering is the benefit of the work of mourning." ${ }^{38}$

Melancholia, however does not accept the traumatic experience, but seems to bury the event deep within. Melancholia seems to take a different turn from that of mourning, in which Ricoeur describes as "the universe seems impoverished and empty. ${ }^{39}$ Melancholia is occupied with the sense of self and causes a person to become an introvert. The "Holocaust Tower" seems to hide itself from the realization of change, anchoring the melancholic feeling within, with no exit from the past.

The Architecture of the Jewish Museum lends itself to the collective memory of the Jewish past in Berlin. The spaces reflect upon the turmoil of the past events, by delving into human senses, thus triggering emotional responses

\footnotetext{
${ }^{36}$ According to Ricoeur, mourning "is regularly the reaction to the loss of a loved person, or to the loss of some abstraction which has taken place of one, such as one's country, liberty, an ideal, and so on." Ricoeur, 71

${ }^{37}$ Ricoeur $_{\perp} 71$.

38 Ibid, 73.

39 Ibid, 73.
} 
to the space. The way the museum is experienced, however, depends on the personal memory and experiences of the visitors as they move through the spaces. Depending on the connection to the place, the emotional responses may vary. 


\section{Part Two: Architecture as Skin}

\section{Chapter Three: Skin Manipulation}

\subsection{Defining Skin}

The skin experiences the stimuli to the physical world; it collects information through its neurological pathways and relays them to the organs within the body that this stimulus is projected to:

The skin is the oldest and most sensitive of our organs, our first medium of communication, and our most efficient protector...Even the transparent cornea of the eye is overlain with a layer of modified skin...Touch is the parent of our eyes, ears, nose, and mouth. It is the sense which became differentiated into the others, a fact that seems to be recognized in the age-old evolution of touch as 'the mother of the senses. ${ }^{40}$

The skin, however, is not only a mediator between the collection of information and the organs which experience the information. The skin is able to collect and experience the information through itself. It seems that the skin in itself has the ability to project stimulus and can be stimulated by sensual experiences. To better understand this analogy, let us examine how the skin of a human being functions; it reacts to the exterior stimulus that surrounds us. Any abnormality in temperature, pressure or even emotional stimulus, is gathered by the skin then passed through the synapses to calculate a response to the stimulus. The response then is transferred back through the skin to confront the stimulus through a reaction; the latter is our physical reaction to the world.

The haptic senses play a large role in the experiences of visual stimuli and can be directly affiliated to them. Touch is the primary sense which develops in the fetus; without this sense it is difficult to associate ourselves within the

\footnotetext{
${ }^{40}$ Pallasmaa, 11.
} 
physical world through perception: "Human babies have been observed to have enormous difficulty surviving if they do not possess a sense of touch, even if they retain sight and hearing. Babies who can perceive through touch, even without sight and hearing, fare much better."11 Touch, however, cannot be disassociated from vision, as the skin seems to act as a sensory organ that can transform the touch stimuli to recognize shapes, textures and temperature differentiations. According to Juhani Pallasmaa, "All the senses, including vision, are extensions of the tactile sense; the senses are speculations of skin tissue, and all sensory experiences are modes of touching and thus related to tactility. Our contact with the world takes place at the boundary of the self through specialized parts of the enveloping membrane. ${ }^{42}$ This said, since the two experiences seem to be inseparable, it appears that the skin has the ability to project itself as a visual experience.

The inseparability of the haptic senses and the sense of vision can be manifested in the ability to remember. It can be said that, "The eye is the organ of distance and separation, whereas touch is the sense of nearness, intimacy and affection. The eye surveys, controls and investigates, whereas touch approaches and caresses. ${ }^{\text {n3 }}$ Touch solidifies the reality of vision. To see something impacts the visual cortex, which is directly affiliated to the mind. Vision also has the ability to touch, however this manifestation is through the collaboration of past memory of material tactility. It seems that touch and vision are connected through the ability to store memory of past tactile experiences.

\footnotetext{
${ }^{41}$ Haptics, http://en.wikipedia.org/wiki/Haptics

${ }^{42}$ Pallasma, 10.

${ }^{43}$ Ibid, 46.
} 
We know that every surface has its specific code which is revealed to us through touch. For example, a pebble on the beach is soft, cool and heavy. Without the tactile knowledge of the stone, we would most likely not have the data to comprehend the stone's qualities. It is within this gesture that we have the ability to assume that visual encounters cannot be disassociated from touch and vice versa. Visuallity also plays a significant role in the interpretation of touch. We have the ability through touch to associate ourselves to the intrinsic qualities of the materials that surround us; we are able to verify weight, temperature, texture.

\subsection{Objectives of Skin Manipulation}

This section discusses the intrinsic nature of using "skin" in architecture and its affiliation with $\mathrm{CT}$ to create a place in which the visitor to the space can qualifiably interact. The skin acts as a way to express outwardly the intentions of the Architecture within the building. It is the first mode of communication to the visitor. The importance of the skin will not only be studied as a means of introduction to a building, but also as a mediator between the visitor and the owners of place. The study will be done using specific case studies exemplifying the importance of skin manipulation and the use of CT in the skin to project an easier transition between quantifiable to qualifiable space. We will explore a way to bring CT out from a state of in-betweeness to enhance that which defines Place.

There is a connection between the skin and the building's interior. Without an affiliation to the interior, the memory of place, and the inhabitants, the skin 
might provoke a sense of being detached, thus distancing the connection between the artifact and ritual within. By creating this distance, the materiality of the exterior may be projected as merely a functionalist approach to enclosing a building. Johani Pallasma remarks in her book The Eyes of the Skin that the use of modern material technologies in Architecture, mainly the skin, seem to diminish the building's connection of the body and memory from the exterior; in this case, disconnecting the ritualistic space from the connection of the skin in Architecture. Pallasma states:

As buildings lose their plasticity, and their connection with the language and wisdom of the body, they become isolated in the $\mathrm{cool}$ and distant realm of vision. With the loss of tactility, measures and details crafted for the human body-and particularly for the hand-architectural structures become repulsively flat, sharp edged, immaterial and unreal. ${ }^{44}$

This claim becomes of great interest when we begin to discuss the role technologies play within Architecture and social relationships of human beings. It seems that the technologies we implement begin to define the way we see ourselves in relation to our surroundings. The technology begins to define us as we begin to converse within the technology. A new idea of spatial relationship is created, that of the human interaction with the electrical world, and that of our relationship to Architecture. Architecture exists through the intimate relationship between the artifact and the ritual. The ritual is expressed through the interconnectivity of the human body through space. As we begin to define our lives through the means of technological instruments and cyberspace, the relationships of the ritual and the artifact will begin to shift as well. No longer is

\footnotetext{
${ }^{44}$ Pallasma, 30.
} 
there only the connection of place through the haptic senses of the body, but the electrical connectivity between body and the world. 


\section{Chapter Four: Skin as Expression}

\subsection{Architects}

This section of the thesis examines three architects and their methods of skin manipulation. Jean Nouvel, Toyo Ito and Christian Moeller discuss the various systems of manipulation through materiality and innovation for design. The skin will be broached using works that transcend from the early 1980's to the present.

\subsubsection{Jean Nouvel}

Since the innovative expression of skin in Architecture through Jean Nouvel's and Ito's work, architects have begun to investigate the importance of the skin. The skin in Nouvel's work seems to reflect and adapt to the surrounding area and exterior stimuli like the sun, or wind. These stimuli formulate an expression on the building's skin; this, in turn, binds the Architecture with site. The importance of transparency, shadow and light plays within most of all his designs. In his projects the skin seems to represent an invitation into the interiority of the building and site.

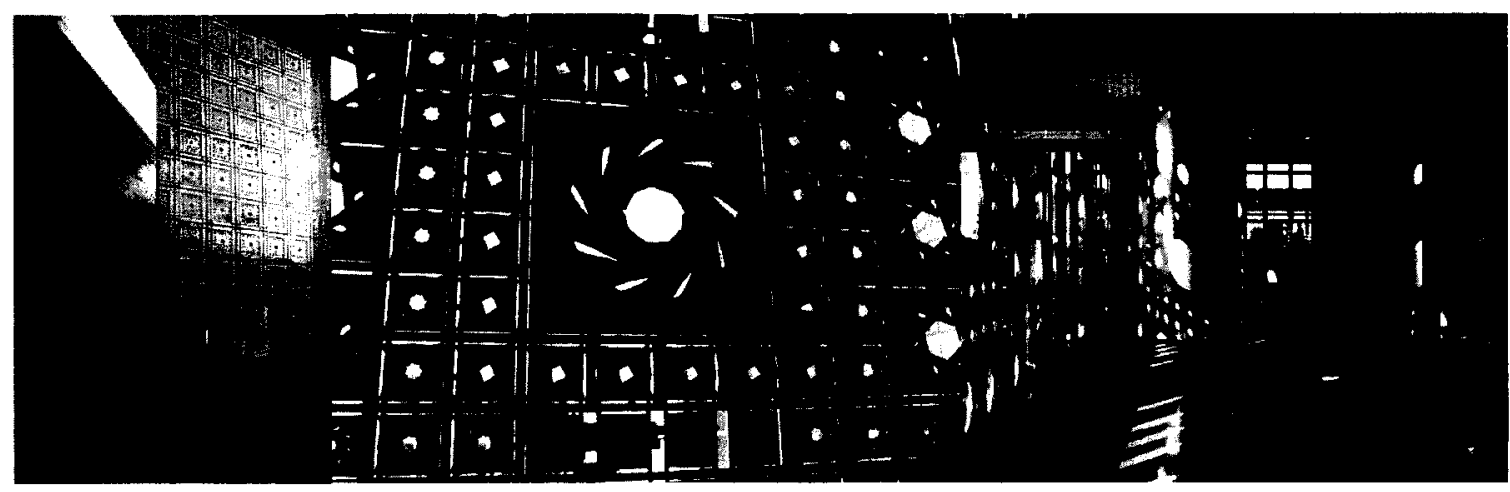

\section{Figure 4. Arab Institute (Jean Nouvel)}

This figure shows different views from the Arab Institute located in Paris, France commissioned in 1980. The images illustrate the manipulation of the skin by using mechanical apertures to adjust lighting in the building. 
Nouvel's earlier Project "Arab Institute" in Paris, France, is a successful project that initiates the surrounding atmosphere. The building's façade boasts 240 mechanically controlled oculi that open and close every hour. The ambiance of the sun within the interior of the building can be controlled, which is often used in Islamic Architecture for climate control.
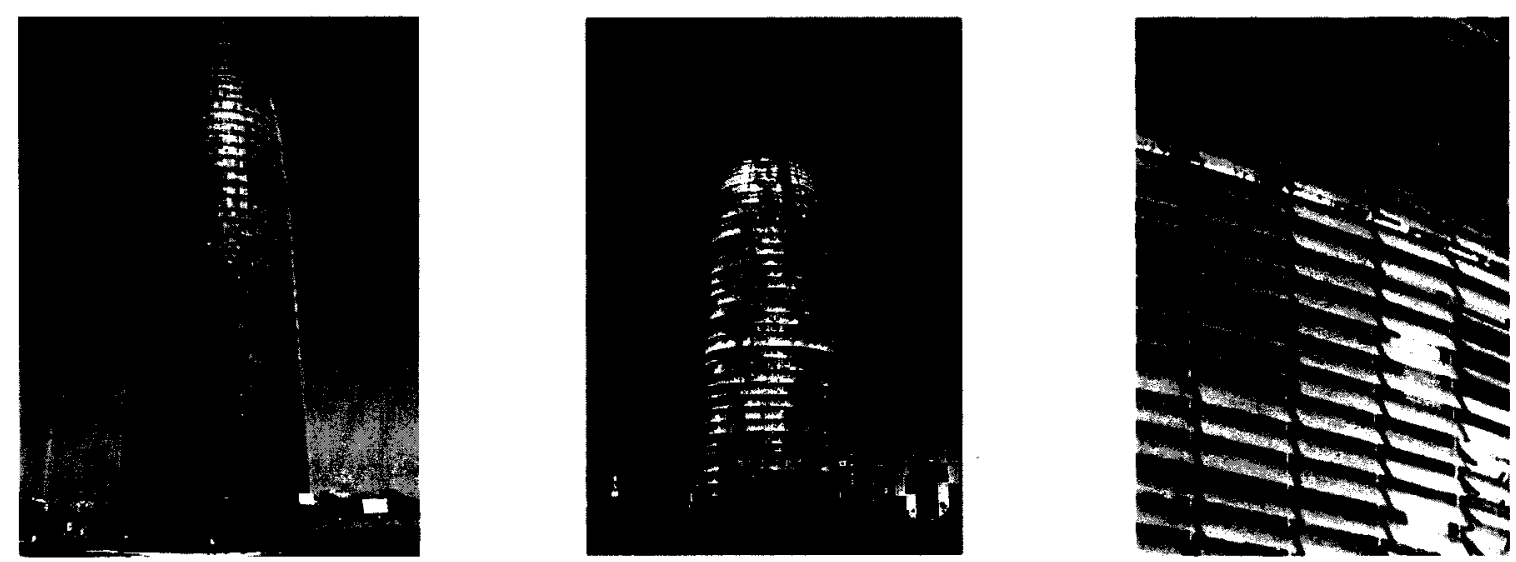

Figure 5. Agbar Tower (Jean Nouvel)

This Figure shows various images of the Agbar Tower located in Barcelona Spain. It opened in June 2005. The third image shows the coloured glass panels.

The "Agbar Tower" was commissioned in Barcelona, Spain in July 2005. It stands 144.4 meters tall and is similar to the "Arab World Institute" since the movement of its skin controls light filtration. The building boasts 56,619 transparent glass panels and coloured aluminum panels in 25 different shades that are tilted at specifically calculated angles to deflect direct sun light from entering into the building. Jean Nouvel states:

The uncertainties of matter and light make the campanile of Agbar vibrate in the skyline of Barcelona: a faraway mirage day and night; precise marker to the entry of the new diagonal that starts at Placa de las Glorias. This singular object becomes a new symbol for an international city. ${ }^{45}$

$\overline{45}$ Jean Nouvel. "Torre Agbar"January 2, 2006. www.arcspace.com/architects.nouvel/agbar/agbar.html. 
The tower's skin seems to reflect the colours surrounding it. The glass panels reflect the movement of the streets and the sky, while the colours orange, red and brown - represent the connection to the earth. The top of the tower, which consists of blues and whites, represents the sky. The skin embodies the attachment of the tower to the culture of the city. Nouvel describes the tower as a geyser, "it is a fluid mass that has perforated the ground-a geyser under permanent calculated pressure. ${ }^{46}$

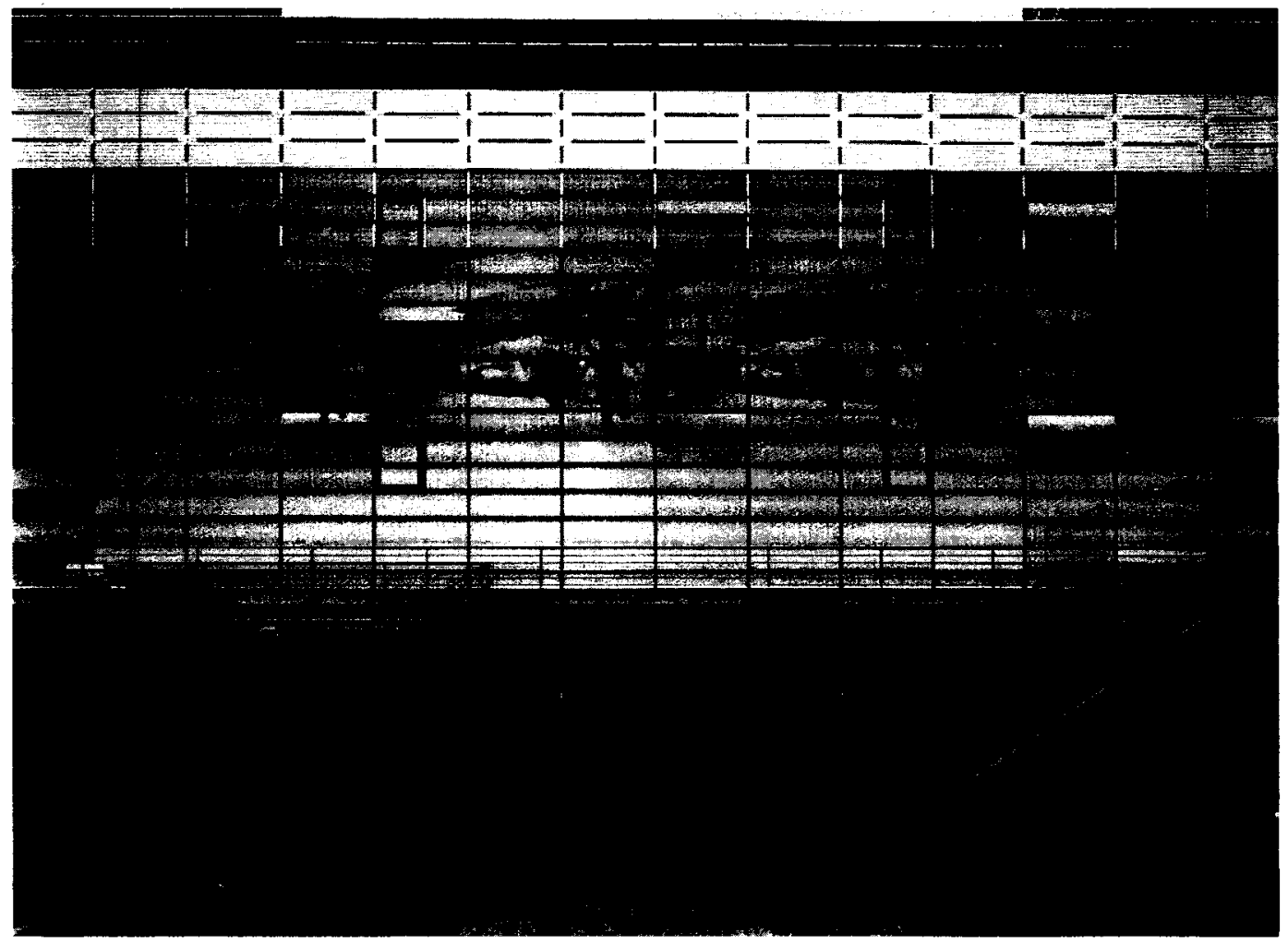

Figure 6. Euralille Development (Nouvel)

This figure shows an image of the façade that Nouvel has used Silkscreening to integrate the building with the site. The building was built in Lille, France and opened in 1994.

${ }^{46}$ Jean Nouvel. "Torre Agbar"January 2, 2006. www.arcspace.com/architects.nouvel/agbar/agbar.html 
The Euralille Development in Lille France is a multi-functional community and high speed rail centre which makes a direct connection from Paris to London. The facility boasts several shops, a business school, sports centre and cultural centre. The building is supposed to create connectivity between the rail system and the various other buildings surrounding it in order to bypass the highway that creates a periphery, and make the space more accessible to the pedestrian scale. Nouvel uses the method of silk screening to incorporate the building to site. This method creates a narrative of the pedestrians' activities and movements as they move through the architecture. By connecting the exterior skin to site using colours, light and silkscreen, Nouvel has the ability to create a dialogue between the surrounding buildings and activities. Nouvel uses the manipulation of the exterior skin to create a narrative between the surrounding site and its occupants.

\subsubsection{Toyo Ito}

The fundamental resolution of Toyo Ito's work is a fusion of physical and virtual worlds and their relationship to how space is to be experienced. The work ties within the urban fabric and investigates the extremes that seem to be presented within private living and working. Ito's interests of the skin in architecture are expressed through the outside and inside dichotomy. Ito describes his Architecture as "clothing" for the urban dwellers. This phrase means that there is a line that separates the intimacy of private life, expressed as the interiority of the body, and the public aspects of life bound with city, such as clothing. Ito's Architecture is bound to this philosophy; however, through skin manipulation Ito 
presents a fusion between exteriority and interiority. Through the virtual world of CT, working and living have become closely bound and it is this dialectic of living that interests Ito's manipulation of space. In an interview with Colin B. Liddell Ito explains:

Now in the $21^{\text {st }}$ century, it's more a condition where living and working, playing and working, they are all intermingled. You play while you work, you do your living while you work. So, in this sort of confused condition of contemporary city life, I feel like I want to bring into my architecture. ${ }^{47}$

With the infiltration of electronic media into our environment, Ito explains that it is important for the skin of Architecture to act as a mediator that adjusts ourselves to the information environment. Ito explains,

People, when clad in a mechanical suit called automobile, had their physical body expanded. People clad in a media suit have their brain expanded. Architecture as media suit is the externalized brain. In the whirlpool of voluminous information, people freely browse through information, control the outside worlds and appeal themselves to the outside world. Instead of appealing to the outside world by armoring ourselves with a hard shell-like suit, people do so by wearing light and pliant media suit which is a figuration of information vortex. ${ }^{48}$

Architecture, as a media suit, is a metaphor for how the integration of CT into the fabric of Architectural space is changing the way architecture is being navigated.

\footnotetext{
${ }^{47}$ Colin B. Liddell ,"Toyo Ito interview: architecture week". Jan, 2007. www.architecturalinterviews.blogspot.com

${ }^{48}$ Toyo Ito, "Image of Architecture in electronic age". Designboom, 2010 wuw.designboom.com/eng.interview/ito_statement.html.
} 

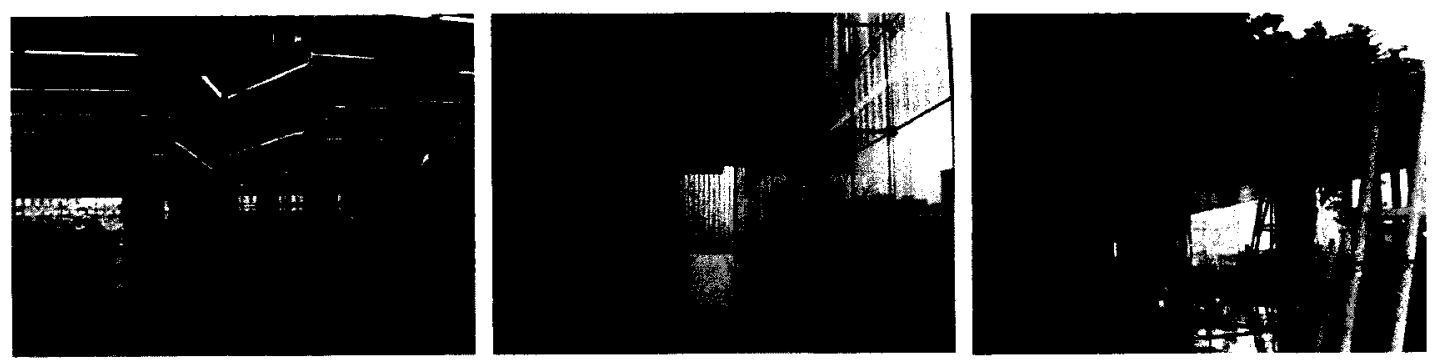

\section{Figure 7. Mediatech (Toyo Ito)}

The figure shows three images of the Mediatech centre built in Sendai, Japan in 2001 by Toyo Ito. The first image shows what Ito refers to as tubes, the second and third the transparent façade (skin) that creates the connection of interior exterior.

The "Mediatech" located in Sendai, Japan, is a great example of Ito's philosophy concerning CT and Architecture. The concept of the Architectural design embodies new ways the modern person experiences the world through CT. Ito says that paintings and books are becoming ever more accessible through electronic media (ie: internet), which may cause a breakdown in the traditional Architectural archetypes, such as the museum, library and gallery spaces. The "Mediatech" focuses on a mixed program of library, art gallery and a visual/auditorial media centre. The three main elements of the building are formulated through what Ito calls "plate", "tube" and "skin". The plates signify the horizontal spaces that make human interaction possible: "By 'Plate' we mean six square slabs, and we attempted to diagrammatically express different modes of communication between people and things that may vary depending on the media used" 49 The tubes are described as tree like structures that connect the communication between the horizontal slabs. The 13 tubes act as structural elements of the building as well as wells that connect light and utility mobility within the building. Ito describes tubes as,

\footnotetext{
49 Toyo Ito, "Image of Architecture in electronic age". Designboom, 2010 www.designboom.com/eng.interview/ito_statement.html.
} 
13 tree-like elements that vertically penetrate the plates to organize and integrate the latter. They are the flexible structural members acting also as the vertical traffic line and as the space where energies (light, air, water, sound, etc.) and information flow. Presence of the tubes creates movements of natural elements and of electrons in the homogeneous spaces defined by the plates. ${ }^{50}$

The skin separates the interiority from the exteriority of the building. Ito's manipulation of the skin specifically creates a connection between the interior and exterior spaces, by allowing for a fluid visual connection to site. The skin is a continuous curtain wall of glazing which spans the whole façade of the building without creating separation between floors. The skin plays a large role in the connection of site with the activities within the building. According to Shira Brand's article,

In his architecture Ito attempts to introduce the image of progress 'advance or development towards completion, betterment, etc; improvement', using the most advanced technology and putting it on display. Despite this, Japanese concepts of simplicity and minimalism remain at the heart of the design: there are no messages on 'screen walls', the latest trend in Toyo Ito's buildings for the media 'the main means of mass communication (esp. newspapers and broadcasting) regarded collectively', but it is through transparency that the development of the mediateque on the inside is seen. The wideranging definition of media gives rise to a rich, complex multifunctional programme involving interaction between different environments. ${ }^{51}$

Ito's Architecture is very successful since he makes connections between public and private through the manipulation of the skin specific to the various functions located within those spaces. Ito says that the ability to see into the building through the glazed façade creates a media relationship as it interacts between various environments. The design promotes the importance of

\footnotetext{
${ }^{50}$ Toyo Ito, "Image of Architecture in electronic age". Designboom, 2010 www.designboom.com/eng.interview/ito_statement.html.

${ }^{51}$ The Concise Oxford Dictionary, Shira Brand and R.E. Allen, ed. (Oxford University Press, 1991).
} 
connectivity of information and forges it together within a materialistic configuration.

\subsection{Christian Moeller -Communication Technologies relationship with skin}

The relationship of CT and the skin in Architecture is broached by the contemporary artist/architect Christian Moeller. Moeller investigates the connection between Architecture and the various sensorial implications involved using CT. The projects investigate the interactions between the populace and the living city, putting into context what would usually be overlooked. Moeller's investigations stem from the notion that we become so accustomed to the noise and sights within a city that we begin to remove ourselves from the details surrounding us. Moeller remarks:

A blind child, given sight with the help of an operation, was only able to see white noise. He was unable to build a bridge to the world of things he's known by feeling and hearing, and saw instead a thunderstorm of dashes, static and angry pattems coming down on him, an incomprehensible image world without order. He kept his eyes shut to escape this noise of light, and wished himself back to the orderly sensorium he had inhabited before. We, with our vision trained to make sense of what we perceive, can't imagine the world as he must see it, a maximum image so totally undecoded.

In order to tie the connection between $\mathrm{CT}$ and its ability to converge with memory using the skin, we will investigate three of Moeller's installations.

${ }^{52}$ Christian Moeller, A Time And Place-Media Architecture (Switzerland: Lars Muller Publishers, 2004 ), 5. 

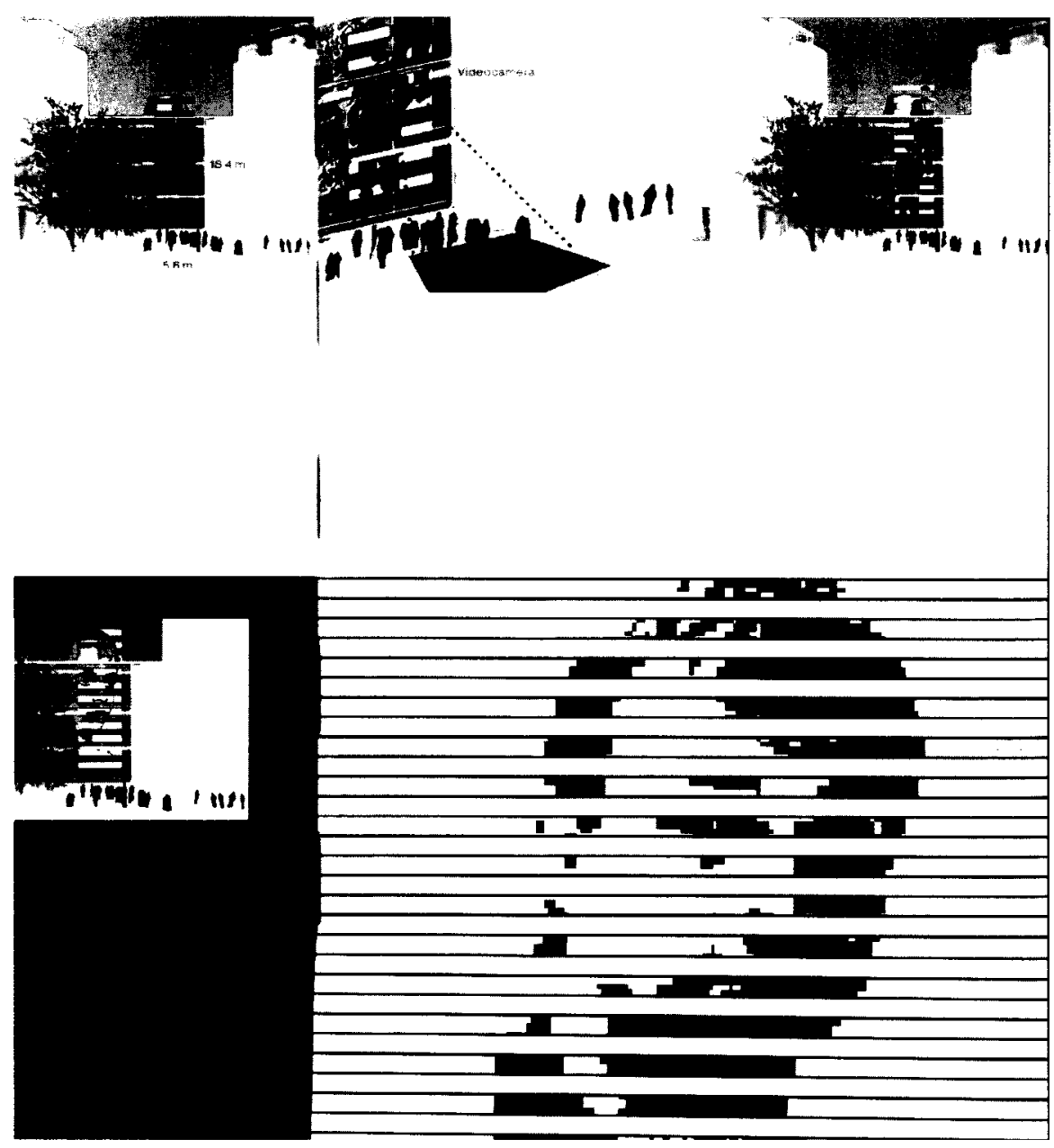

Figure 8. Bitwall 2 (Moeller)

This figure shows the project Bittwall 2, developed for Bielefeld Station in 2002 by Christian Moeller.

The first project under investigation is called "Bitwall 2", developed for the façade of a railway station in Bielefeld, commissioned in 2002. The project is comprised of an 18.4 meter high by 5.6 meter wide bitwall screen, faceted to the front façade of the station. The entrance of the building is under video surveillance, projecting the movement of the visitors onto a screen. The screen is segmented into separated strips, to offer an optical illusion to the viewers of the installation. The idea of the installation was that the eyes had potential to fill in the missing data on the projection screen. An important notion that can be 
divulged from the project is the introduction to place, by involving the populous in the material of the building itself. It is through one's own body that place can be experienced. Is it possible that by involving an electric projection of the body onto a façade, that the projection will impact the intimate relationship of the visitor and the owners of place?

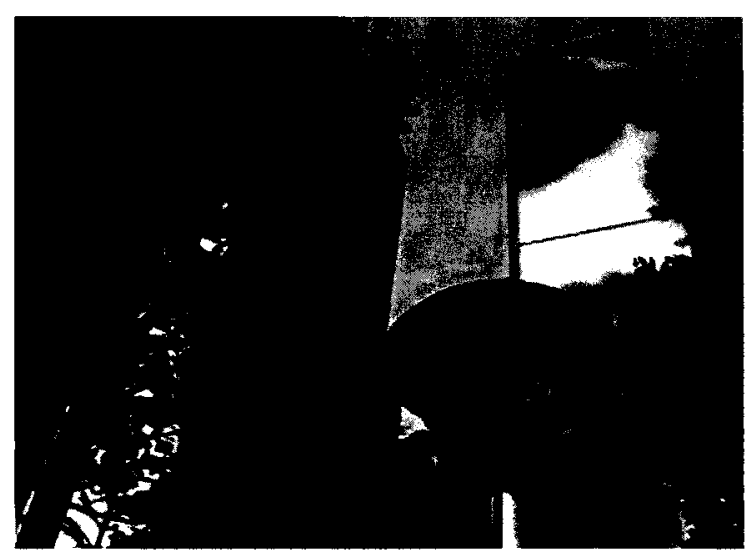

\section{Figure 9. Nosy (Moeller)}

This figure shows the project Nosy commissioned for Osaka City in 2006 by Christian Moeller

The second project, similar to the first, is called "Nosy". This was commissioned for Osaka City in Japan in 2006 . The project actively records and projects the surrounding environment of the city onto three 43 foot high panels. The project seems to intensify the physical connectivity with place without understanding what place entails. The digital skins on the building begin to formulate a narrative of the occupants and visitors to the place and within the area surrounding it. The wall picks up visual fragments of the surrounding area, and creates a dialogue between the surrounding area and the building. Giuliana Bruno indicates that the connection to memory is made through the collection of images: 
Let us recall that the art of memory was itself a matter of mapping space and was traditionally an architectural affair. In the first century A.D, more than a hundred years after Cicero's version, Quintilian formulated his architectural understanding of the way memory works, which became a cultural landmark. To remember different parts of a discourse, one would imagine a building and implant the discourse in site as well as in sequence: that is, one would walk around the building and populate each part of the space with an image. Then one would mentally retraverse the building, moving around and through the space, revisiting in turn all the rooms and that had been decorated with imaging...memory stems from a narrative, mobile, architectural experience of site. $^{53}$

Moeller's expression of combining imagery on the façade of the building brings to fruition the idea of imagery mapping proposed by Bruno. By mapping out the spaces through imagery, one may experience a connection to that of memory. The experiment that Moeller installs on the façade further emphasizes the narrative since he creates a narrative from the movement and the pedestrian's experience of site. For a single moment the dialogue of the surrounding area is faceted on an immobile structure, bringing forth the connected dialogue between the place and the populous through CT.

${ }^{53}$ Bruno, 20. 

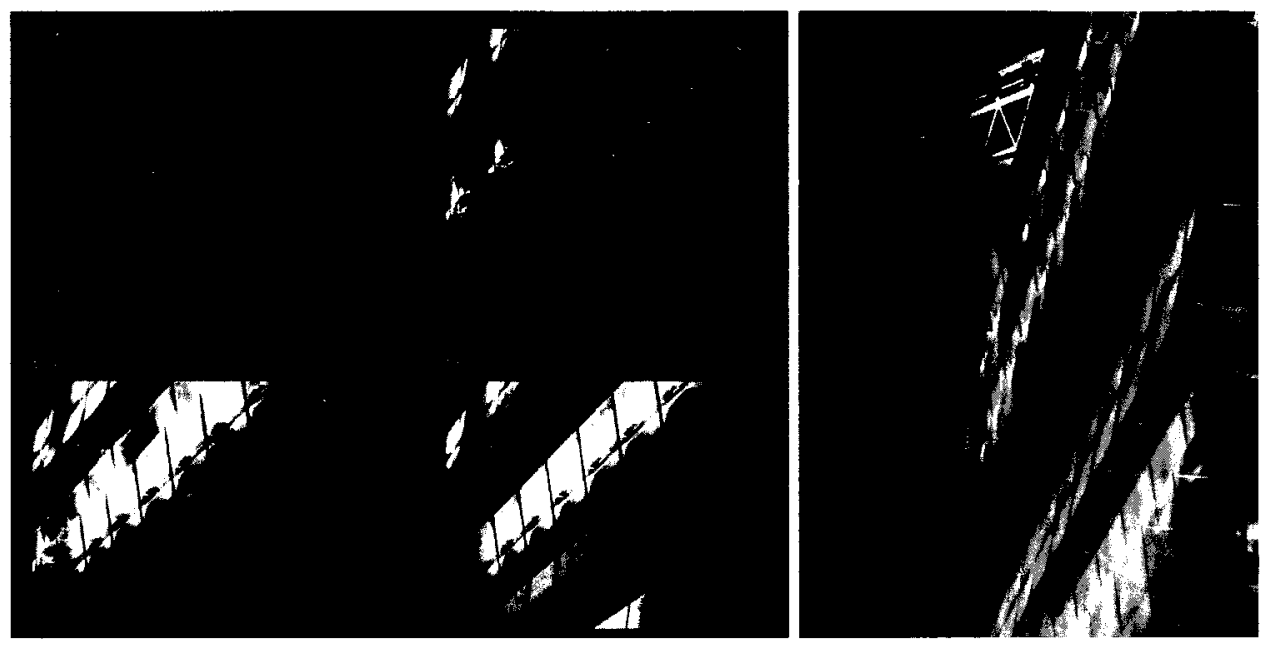

Figure 10. Kinetic Light Sculpture (Moeller)

This figure shows the Kinetic Light Sculpture commissioned for Frankfurt in 1992 by Christian Moeller. The image on the left illustrates the different colours emitted due to temperature differences.

The third project is entitled "Kinetic Light Sculpture," commissioned in 1992. It is the façade of the Zeilgalerie in Frankfurt. The project investigates the skin's reaction to exterior weather patterns of the surrounding area by denoting specific colours in reaction to the temperature and to the wind characteristics. Moeller describes this project as being an important stepping stone in his progressive work in electronic media. He remarks:

We decided to control the constantly changing transparency and colour of the resulting light façade by the weather station on the roof of the new building. The façade consists of a colour cluster on the wall varying in position and size, and a horizontal spectrum in the form of a white linear diagram on the upper third of the installation surface. In front of the building, there was a second façade layer made of folded perforated metal panels. In the space between the two layers, $120 \mathrm{HQI}$ spotlights were mounted on catwalks. Each spotlight had a movable lid which we could control by computer in order to vary the emerging light tones from yellow to blue. $^{54}$

The data collected by the computer was then responsible for the determined colour on the façade of the building. Cooler temperatures caused the

\footnotetext{
${ }^{54}$ Moeller, 158.
} 
panels to turn blue, while warmer temperatures created a yellow hue. Not only was temperature involved but also wind velocity. The wind in this project was responsible for the movement of the colours on the façade. As the wind velocity changed, so did the movement on the façade. Moeller also concerned himself with the ambiance of the streets. A live recording was made of the city bustle, emitting light at the top of the building. Moeller seems to turn quantifiable data, measured by the weather station, into qualifiable data which creates a sense of life on the skin.
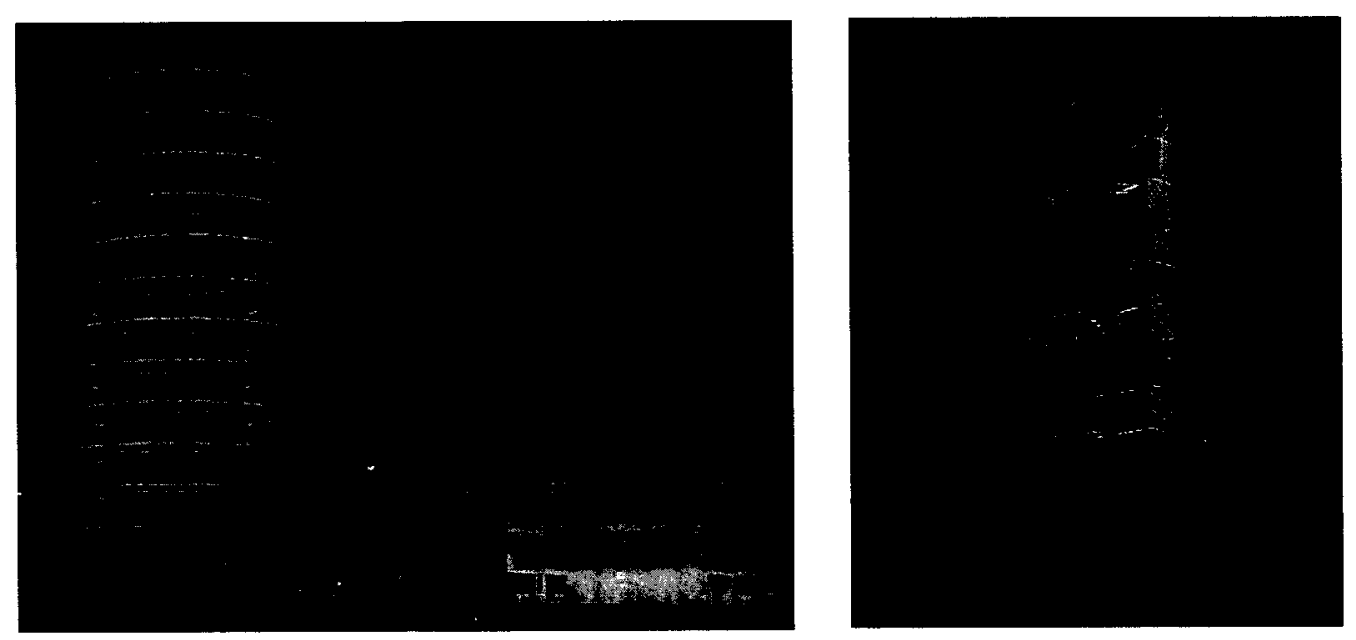

\section{Figure 11. Tower of Wind (Toyo Ito)}

This Figure shows a similar project to Moeller's Kinetic light Sculpture. The Tower of Winds was commissioned for Yokohama, Japan in 1986.

Moeller's "Kinetic Light Sculpture" is similar to Ito's "Tower of Wind," built in 1986 in Yokohama Japan. Ito's work explores the transparencies of the skin during different moments in the day. During the day the building appears to be opaque, forwarding a grey hue. At night, however, the façade takes on another nature. Like Moeller, the tower of wind projects the data collected from the surrounding area onto the façade, dictating different colours pertaining to the 
fluctuation of noise on site. The use of light as a representation of the elements creates an urban bond from building to site, enabling the structure to become part of the continuous motion of the city even after the occupants have left. It appears that the building has not been turned off.

By creating a visual and experiential connection between site and the façade, Moeller is able to create a materialistic connection between CT and the building. By using CT as a medium, Moeller is able to create an Architecture that reacts to the sensual data collected from site. By creating an experiential dialogue between site, occupants and the building, Moeller is able to use CT as a medium of expression fused in Architecture. 


\section{Chapter Five: Methodology of Skin Manipulation}

\subsection{Criteria for Evaluation}

All the senses, including vision, are extensions of the tactile sense; the senses are speculations of skin tissue, and all sensory experiences are modes of touching and thus related to tactility. Our contact with the world takes place at the boundary of the self through specialized parts of the enveloping membrane. ${ }^{55}$

Johanni Pallasma states that people experience the world by interacting within it, using their skin as a primary sensory organ. The skin connects us to the world through its ability to create a relationship to spaces through memory manipulation. This creates a connection to place. In order to create a connection to place, we will examine the possibilities of creating a connection between site, transitory space and the owners and visitors of space using CT as a medium of exploration. Two important questions must be raised at this time: Can the skin create a bridge between the physical and electrical worlds to make the artifact and the ritual more meaningful? Can CT be integrated into Architecture using the skin to create a new way of experiencing place within a society filled with Communication Technology relationships?

First, we must explore a series of rules pertaining to the differentiation in the two mediums, that of CT and skin. CT will be broached using the following criteria: 1. Because CT can be carried all times, it loses the ability to be connected physically to site. 2. CT renders the user to a state of "Inbetweeness". 3. The immaterial nature of information must be broached in order

\footnotetext{
${ }^{55}$ Pallasma, 10.
} 
to create a materialistic connection. We may ask the question: How does one connect CT so that it becomes part of the experience of Place? To solve this problem CT will be required to become connected to site, the functions of the facility and the relationships of the public and privacy within the institution. The methods will be extracted from the three Architects mentioned in the previous chapter: Nouvel, Ito and Moeller. Moreover, we will explore how their individual methods of skin manipulation will aid in the integration of CT into Architecture.

\subsection{Immaterial Material}

Vilem Flusser extrapolates how information is beginning to de-materialize through the way it is presented using CT. He says that information was predominately presented through material things, like books, newspapers and paintings:

The Information that now floods our environment displacing the things in it is a kind that has never existed before: It is immaterial information. The electronic pictures on the television screen, the data stored in computers, all the reels of film and microfilm, holograms and programs, are such 'soft' ware that any attempt to grasp it is bound to fail. ${ }^{56}$

The information was represented as a material manifestation of code that when read and decoded could be understood. The "immateriality" of information today is does not seem to be tangible. This begs the following question: Which way can immaterial information inform Architecture when it doesn't seem tangible?

\footnotetext{
${ }^{56}$ Vilem Flusser, The Shape of Things: A Philosophy of Design (London: Reaktion Books, 1999),86.
} 
To answer this question, information should not be categorized as "immaterial" or "material," but should rather be broached from another direction; how information may inform space.

The method tying CT to Architecture will be undertaken by connecting real time video images of portions of the university and site into the building's fabric. The images will be transposed onto the surfaces of the skin in order to inform space. It is not a matter of whether the images can be defined as material, but rather how the information may begin to inform the space, and spatial relationship between space and the occupants. For information to become successful in articulating space the following question must be asked: In what way does information inform the space, and create a dialogue between the occupants? The success of incorporating the images into the Architecture through skin manipulation is in the ability to tie together site, movement and occupants into a space.

\subsection{Analyzing Architectural Methods}

The rules of operation pertaining to the integration of CT and Architecture for the purpose of this thesis are derived from three spatial requirements mentioned in the last section: the functions of the facility, connection to site and the relationships of the public and privacy within the facility. Each of the three requirements will be approached using a connection between the Architectural methods of the Architects specified in section 4 of this thesis. 


\subsubsection{Site}

The importance of the integration of site in the Architecture in relation to CT lies in creating a series of networks throughout the university. The site will be explored on a macrocosmic scale, divulging the experiences, movement and functions on site which will be transposed onto the skin of the building. Site will be broached using a more intimate relationship and public relationship. The external glazing of the predominantly public areas will be wrapped in a physical map of the university. The pathways and routes have been transposed onto the façade, creating a physical connection to the whole of the campus. This method of site manipulation is used as a metaphor to suggest that the Architecture is a microcosm of Carleton University; the design project (building) is the gateway to the university. The intimacy will be broached using the projection of a close proximity of movement to the building, such as pedestrians and vehicles. The networks (public) will function as a series of video surveillance cameras which will be dispersed throughout the university, projecting in real time the movements and activities on campus. The images of the surveillance videos from specific sections of the university will be displayed on the façade of the building. This method offers a real time narrative of the university, where visitors may become accustomed to the spaces on campus. The images project a connection to memory for the visitors, by introducing a visual aid for moving throughout the university before coming in actual contact with the spaces. 


\subsubsection{Function of the Facility}

The functions of the facility will be broached by examining the different faculties and activities using the agora and forum as a metaphor for the design of each space. The exploration constitutes the collective gathering space, private meeting spaces, exhibition spaces, offices, classrooms, residential, as well as auditorium spaces.

The agorian spaces are the exhibition spaces and collective gathering space; these are the spaces which will have a direct affiliation with CT. The reason behind this idea is that the agora is a space or a series of fluid spaces that permit interaction among people. The agora is not organized into distinct parts. It permits the pedestrians to meander fluidly throughout the space, provoking discourse. These spaces will open to the movement of the whole facility, bringing in visual aid from the site to form an expanded dialogue between the occupants within the building and the occupants of site. This will create a unified conversation piece.

The spaces of forum are offices and classrooms. The forum spaces require a sense of authority of forward movement and destination unlike the agora which permitted for sideways movement and dispersal. In these spaces the occupants will become organized rectilinearly, placed in such a way that there is attention to the authority figure and attention to study: "information was presented through the organization of bodies and thus thought. By controlling the movement of the people, information could more easily be presented." 57 The classroom chairs will

\footnotetext{
${ }^{57}$ Richard Sennett, Flesh and Stone: The body and the city in western Civilization (United States: Published as a Norton Paperback 1996), 60-61.
} 
be fixed to the floor, looking forward, facing the podium. The vulnerability of the viewer to the authority of the speaker is caused by the ability to control the movement and attention of the viewer. By placing the spectators in a sitting position, facing the stage (the spectacle), the viewer may not be as easily distracted by a peer, such as happened in the agora. According to Sennett, "The forum differed from the agora in framing this diverse crowd in a more rectangular space, lined on all four sides with buildings." 58 The walls will be white without any embellishments so that the students or workers may not be easily distracted.

The spaces of the agora and forum will be juxtaposed to one another. The metaphor will tie the functionality of the spaces with a qualifiable meaning. The forum is an analogy for the information provided by CT, directed towards the populous through media without being questioned as fact. The space of forum directs information to the classroom (viewer) in such a way that the podium has full authority. The agora acts as a chatroom dialogue. The communication is a plethora of interaction between various groups of people from different cultures and backgrounds. The agora permits for a freedom of movement throughout various spaces, taking in information and presenting reactions to it.

${ }^{58}$ Sennett, 112. 


\subsubsection{Public and Private}

Toyo Ito uses "public and private" spheres as a main theme within his Architecture. The public and private spheres are merging with the increased use of CT in everyday life. This suggests that spaces of work can also become spaces of play. The fusion between work and play is extremely evident in the work spaces since various opacities of material are used depending on how much privacy the employee requires while in the state of work. The idea is to avoid segregating the employee from the rest of the space. The spaces of work will be sectioned off with opaque materials, permitting the employee to become focused with work, while the areas pertaining to dialogue, between customer relations and meeting spaces, will be translucent and inviting. These translucent spaces encourage the occupants to become part of the discussion, while at the same time, keeping movement to a minimum. The spaces of movement will have a close relationship to the movement of the agorian spaces within the building. Curvilinear references will be made to create the interaction of public and private. 


\section{Part Three: The Design of the Gateway to Carleton University}

This portion of the thesis describes the methods behind creating a connection between the inhabitants of the university and its visitors. In order to create this connection, skin is used as the medium to express the relationship between CT and its endeavor to unite qualifiable and quantifiable space. Programmatically the gateway will entail collective gathering space, private meeting spaces, exhibition spaces, offices, classrooms, residential space, as well auditorium spaces. These seven programmatic principles will act as the main focus of spaces on the site.

\section{Chapter Six: Site}

The site under investigation is located at the main O-Train transition space and parking lot, located centrally on Carleton University's campus. The O-Train track runs on a light rail system 8 kilometers from North to South with 5 stops along the way, beginning at Greenboro station in the south and traveling to Bayview Transit Way just west of downtown Ottawa. Currently a small glazed and metal shelter sits on the site providing shelter to the visitors and students of the campus with a 94-space parking lot on the East side. The site sits between two main arteries on the campus, Campus Avenue and University Drive. The surrounding area is comprised of various buildings which house the different faculties. The closest buildings to the west of the site are the Minto centre, Mackenzie and Architecture building which are the main hubs for the Faculty of Engineering and Design. The primary materials used in these buildings are brick, concrete and glazing. The 
same materials are also used in the Maintenance building located to the east of the site.

There is an array of ethnic groups who are studying in the various departments on campus. The university is comprised of six faculties; the Arts and Social Sciences, Engineering and Design, Public Affairs, Science, Business, and Graduate Studies and Research. Carleton University houses 56 different undergraduate programs, 69 Master and 37 Doctoral programs. Along with the academics, the university has a series of extracurricular activities, entertainment, dining, studying spaces and parks. The university is a microcosm of the city which offers a mishmash of private and public programs, agorian spaces and forums.

The particular site was chosen since it connects the north and south sections of the city. The site acts as a gateway to the university; however, the existing site does not have the impact required to relay to visitors the importance of Carleton University as a multifaceted educational hub.

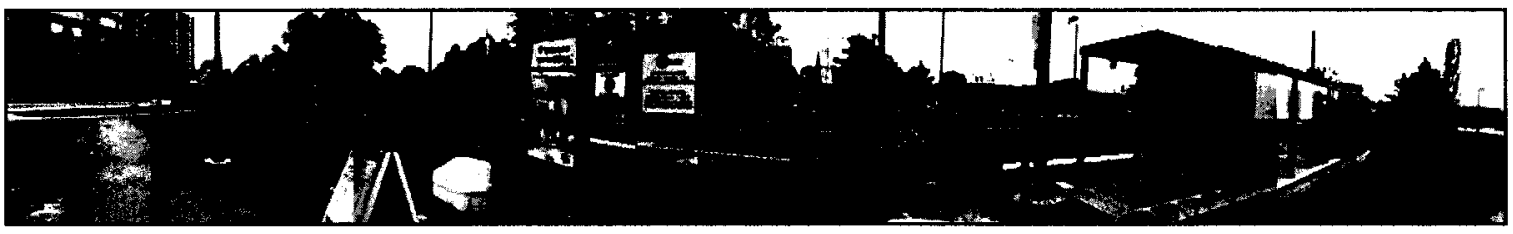

\section{Figure 12. O-Train Site}

This figure shows the O-Train site on Carleton University Campus.

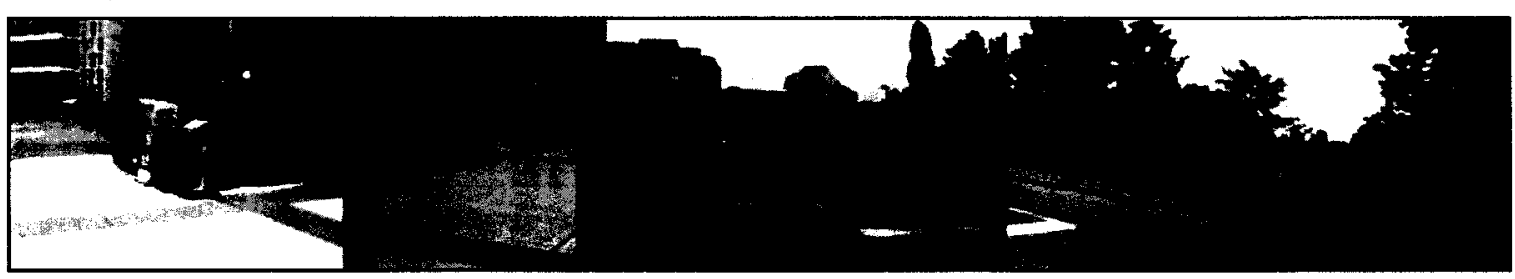

Figure 13. Campus Avenue

This figure shows the site, looking North on Campus Avenue. 
Initially a proposal for a gateway to Carleton University was suggested in the event that an extension to the O-train track would be undertaken. ${ }^{59}$ The plan for the extension of the track was that it would run east from Lebreton Flats to Ottawa University and south-west from Greenboro to Barrhaven; the plans, however, were dropped in 2007, which resulted in major controversies and lawsuits between the city and contracted companies. The cancelation of the extension resulted in uncertainty over ever having an O-train connection that would make feasible the 70 million dollar showpiece that was proposed to be erected over the track. Pauline Tam of The Ottawa Citizen remarks:

Carleton officials had been counting on the north-south line to reduce car traffic, improve transit routes to the campus and create a new building site for a university that's quickly running out of room to expand. Those hopes faded with the cancellation of the train deal, which has also delayed the university's building plans by nine months. ${ }^{60}$

Since the construction of an O-train track is uncertain, Carleton University has begun building two smaller structures on campus which will cost an extra 10.5 million dollars more than the initial plan for the track. The first structure will be 100,000 sq.ft, erected west of the Engineering building housing a Renewable Energy program and a Biomedical Engineering program. The second, larger, structure will be 140,000 sq.ft, adjacent to the Rideau River, which will house a Journalism program, and Public Policy and Administration. The growing

\footnotetext{
59 "The death of Ottawa's north-south light rail dream has forced Carleton University to abandon plans for a new flagship building linked to the system." Pauline Tam, "Death of light rail forces Carleton to scrap \$70M showpiece," The Ottawa Citizen, December 12, 2007, http://forumskyscraperpage.com/showthread.php?t=140075\&page=21.

${ }^{60}$ Tam, 2007.
} 
requirement for new spaces on campus resulted in new structures being built. Unfortunately, this has caused the new O-train gateway plans to be dropped.

Currently, four plans have been drawn up for the future O-train routes, one of which will incorporate a downtown tunnel with a connection to the Ottawa airport. If the plans are to be agreed upon, the completion will take place in 2031 and will cost approximately 3 billion dollars. Presently, an east-west LRT line is to be constructed, from Tunney's Pasture to Blair, with a tunnel running under the downtown. If the plan runs its course, there will be 13 stops along the line; the expected completion date for the new line will be anywhere from 2014-2016.

When the O-train expansion becomes a reality, it will enable commuters to travel throughout the city with ease. At this point the O-train will gain an additional amount of traffic, which will create a need for a gateway to Carleton University. The gateway must reflect the student body, programs and the aura of the university. It will entice visitors and prospective students to become part of campus life.

\subsection{Critique of the existing O-train shelter}

The existing O-train shelter on site is a purely functionalist expression of transition between university and O-train. The shelter sits on both sides of the tracks and is half-enclosed which protects students from rain and snow; however, it is not suitable for extreme weather conditions during the winter months. The shelter currently occupies enough space for approximately 25-30 students, while the platform holds approximately 100 students. At this point the use of the OC transpo bus service is the primary source of transportation for students. When 
the extension of the track is completed, this will pose a huge problem to the fluidity of traffic on the platform and shelter.

The shelter is built to function as a barrier between the students and the elements, and does not take into consideration special relationships between the visitors and the university. The shelter and platform seem to fail as a successful gateway to Carleton University as they lack a connection to the university. When visitors exit the train they are bombarded with purely functionalistic elements. On the one side, the platform opens to a parking lot and on the other it opens to one of the main veins of the university. The visitors' first impression is not of the character and expression of the university, but rather of the purely functional use of a parking lot and street. Another problem is visitor orientation. When a visitor comes to Carleton campus, they will have difficulties finding their way through the university, as there is no indication on site, other than a map, on how to move through it. At this time the students use the shelter and platform mainly as a means of transition between the university and $\mathrm{O}$ - train, nothing more.

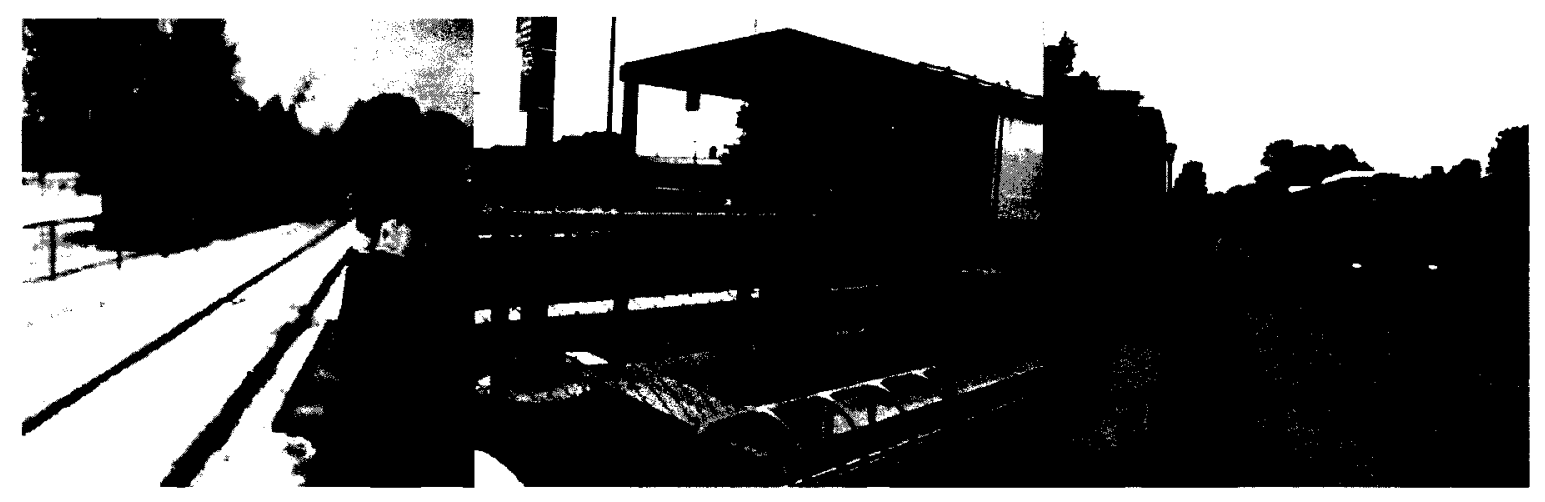

\section{Figure 14. Images of Transportation System}

These images above illustrate the present transportation site conditions on Carleton University Campus. Both the bus and O-train shelter are open to the weather conditions, and do not seem to have enough area to accommodate the many students presently on campus. 


\subsection{Program and Spatial Requirements}

The underlying objective for the gateway to the university is to create a space that accompanies the programmatic requirements for the inhabitants of the campus, while creating an exceptional space that entices visitors to participate with and become intrigued by the university. The Architecture will act as a media porthole, advocating the positive aspects throughout the university. The Architecture will become a microcosm of the Carleton University, entailing a juxtaposition of public and private space.

This section of the thesis will define the spatial requirements that will be required within the gateway. The spaces will be categorized as follows: collective gathering space, private meeting spaces, exhibition spaces, offices, classrooms, residential, and auditorium spaces.

The effective use of $\mathrm{CT}$, using the idea of connectivity on a macrocosmic and microcosmic scale, as well as physically transposed through images, creates an attachment between the university and city (macrocosm), and the gateway (microcosm). The connectivity between site, city and the gateway create a transitional space that simultaneously becomes a space of destination. The multifaceted facility creates an immediate connection between visitor and occupant, work and recreation, as well as travel and destination. CT allows for a network that unifies the activities of the university with the activities of visitors. 


\section{Collective Gathering Space (indoors)}

The collective indoor gathering space is comprised of the public dining area and pit on the first floor of the east building, faculty lounge on the second floor of the west building and the restaurant on the second floor of the east building. Combined, the spaces measure approximately 1,800 to $1,900 \mathrm{~m}^{2}$ in size.

\section{Collective Gathering Space (outdoors)}

The outdoor gathering spaces (gardens) are located on the second and first floors of the west building and the second and third floors of the east building. The spaces are accessible to the offices, faculty lounge, private residences and agorian spaces that use approximately $1,500-1,600 \mathrm{~m}^{2}$ of the building. The first outdoor space is approximately $390 \mathrm{~m}^{2}$ and is located on the first floor, the south side, of the eastern building. It is open to the public dining area. The office outdoor space is approximately $100 \mathrm{~m}^{2}$, the private residential is roughly $198 \mathrm{~m}^{2}$, faculty lounge approximately $220 \mathrm{~m}^{2}$ and the second floor agorian space roughly $672 \mathrm{~m}^{2}$.

\section{Exhibition Space}

The exhibition space is intertwined within the circulation space on the first floor of the west building. The exhibition space represents the six faculties of the university: Science, Arts and Social Sciences, Engineering and Design, Public Affairs, Business, and Graduate Studies and Research. There is approximately $220 \mathrm{~m}^{2}$ allocated for the exhibition space. 


\section{University Offices}

The office spaces are located on the second and third floors of the building on the west side of the track. Each of the three offices has a direct affiliation with the educational infrastructure of the university. The Department of Communication, headed by Director Jason McDonald, and the Department of Research and International Development, headed by VP Dr. Mathison, each have approximately $480 \mathrm{~m}^{2}$ of allocated space. The Executive wing of the South side boasts the offices of President \& Vice Chancellor Dr. Runte, senior advisor to the President Mr. Hood and office of the Rt. Hon Herb Grey.

\section{Classroom/Auditorium Spaces}

The classroom and auditorium spaces are located in the east building on the second and first floors. There are two large classrooms, three conference rooms on the second floor and one auditorium located on the first floor. The two classrooms collectively have a space of approximately $415 \mathrm{~m}^{2}$ and have seating for roughly $264-280$ students. The three conference rooms with entertainment spaces are to be used for discussion groups. Collectively, the spaces are approximately $320-330 \mathrm{~m}^{2}$ and sit roughly $50-60$ people. The auditorium is to be openly used for larger presentations and functions such as the visiting architect lectures. It opens to a large circulation space on the first floor. The space is approximately $340 \mathrm{~m}^{2}$ and sits about 365 people. 


\section{Washrooms}

There are approximately $240 \mathrm{~m}^{2}$ of women's and men's washroom facilities dispersed throughout the building on three floors. Six facilities are men's, while the other six are women's.

\section{Parking Space}

The parking spaces are located underground in the eastern building. To gain access one must enter through the north façade. The garage links with the main building through the fire escape and the tunnel system already available within the university. There are approximately 27 outside parking spots and 74 interior parking spots.

\section{Circulation Space}

The circulation spaces encompass the elevator shafts, stairs, fire stairs and ramps. There are approximately $525-550 \mathrm{~m}^{2}$ appropriated for these functions, excluding the residential facilities.

\section{Platform Space}

There are approximately $360 \mathrm{~m}^{2}$ of platform space on the east side of the track and $360 \mathrm{~m}^{2}$ on the west side of the track.

\section{Transitional Public Space}

The east side of Campus Avenue will be made available students waiting for the O-train or bus. The large open circulation space will enable students easier access to transportation from the university since it will provide a connection with 
the underground tunnel network. It will also allow students easy access to the washroom, information centre and dining facilities. There are approximately 800 $\mathrm{m}^{2}$ allocated for the transitional public space

\section{Residential Accommodation Suites}

The residential suites are offered as an alternative to hotels while officials and visiting critics are at the university. There are two floors of residential facilities which boast a recreation room, dining, private meeting spaces, as well as 30 fully furnished rooms with study spaces and private washrooms. The rooms are approximately $57 \mathrm{~m}^{2}$ each 


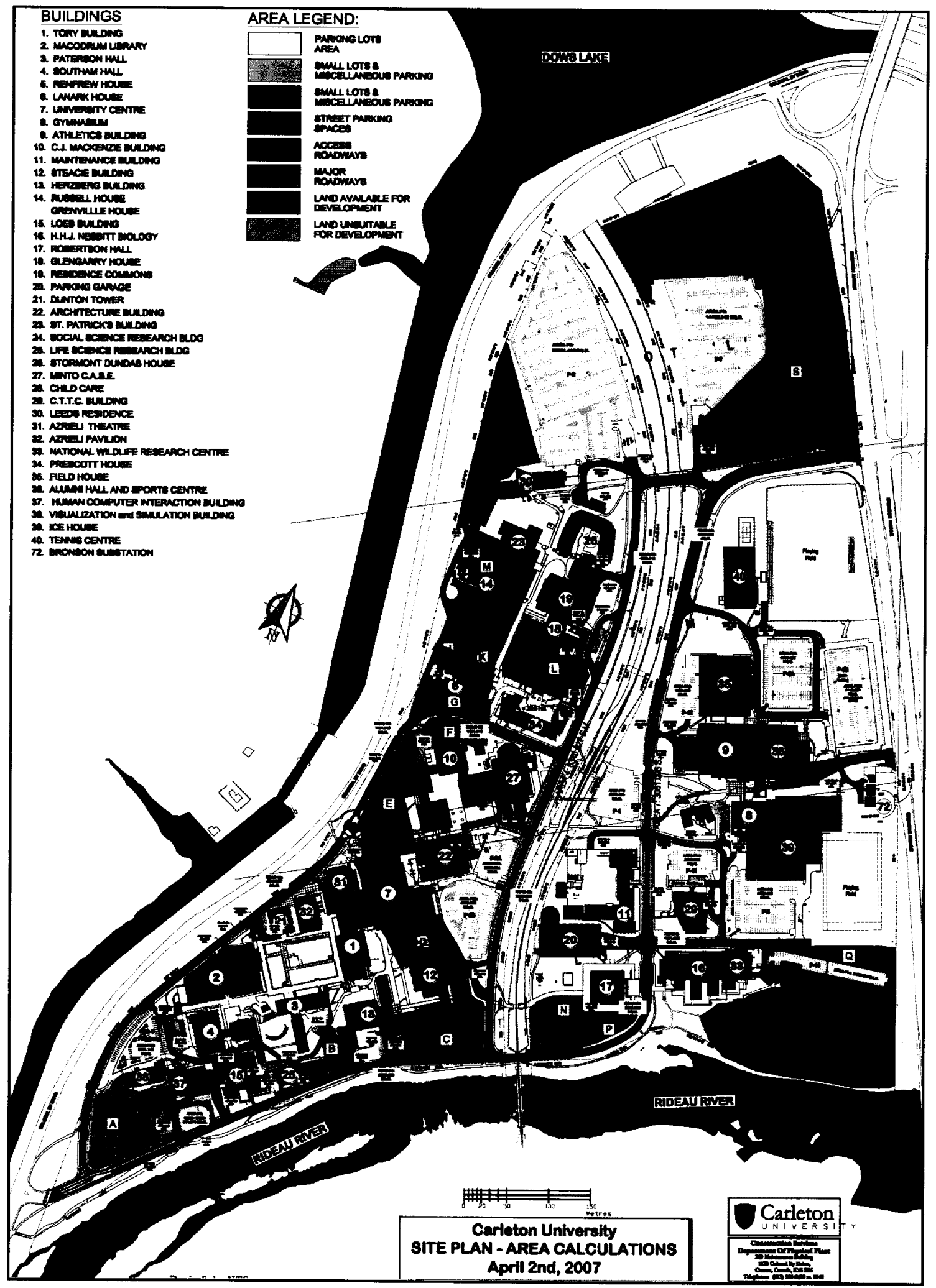

Figure 15. Site Plan of Carleton University

This figure shows the site plan of the university. 

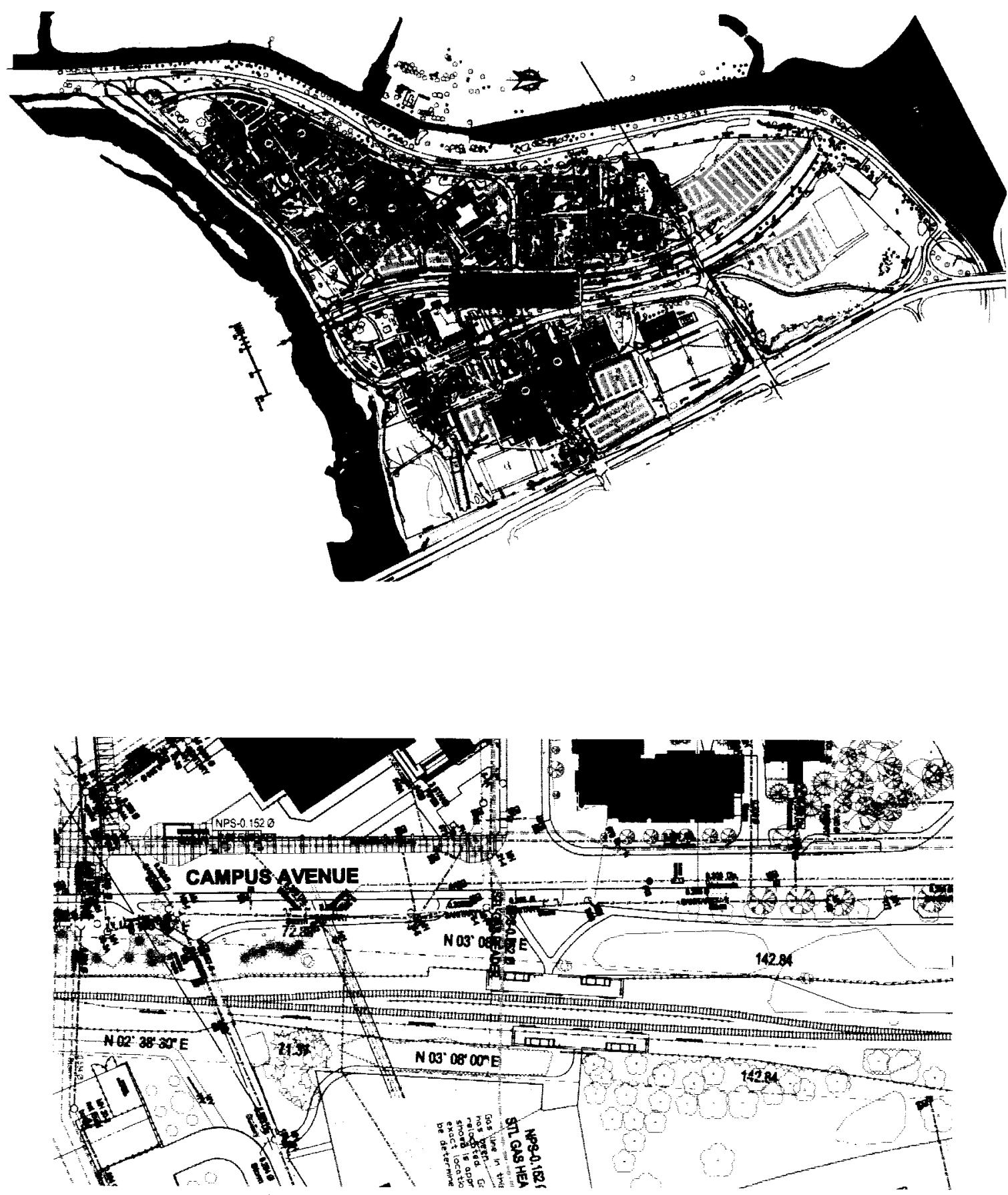

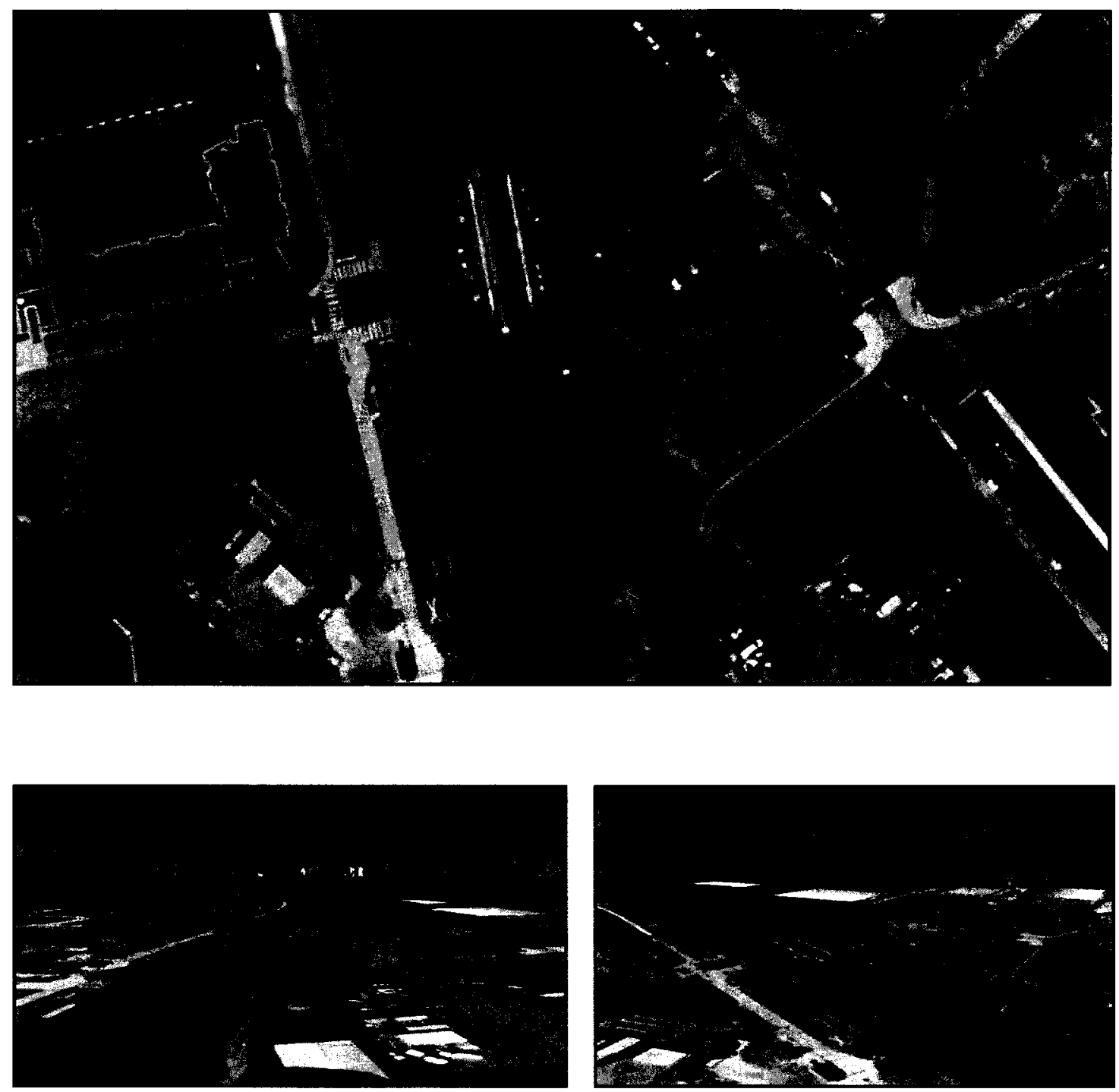

Figure 16: Site Plans

The images on the previous page are of Carleton University Site Plan.

Figure 17: Images of Site

Areal images of Carleton University Campus. 


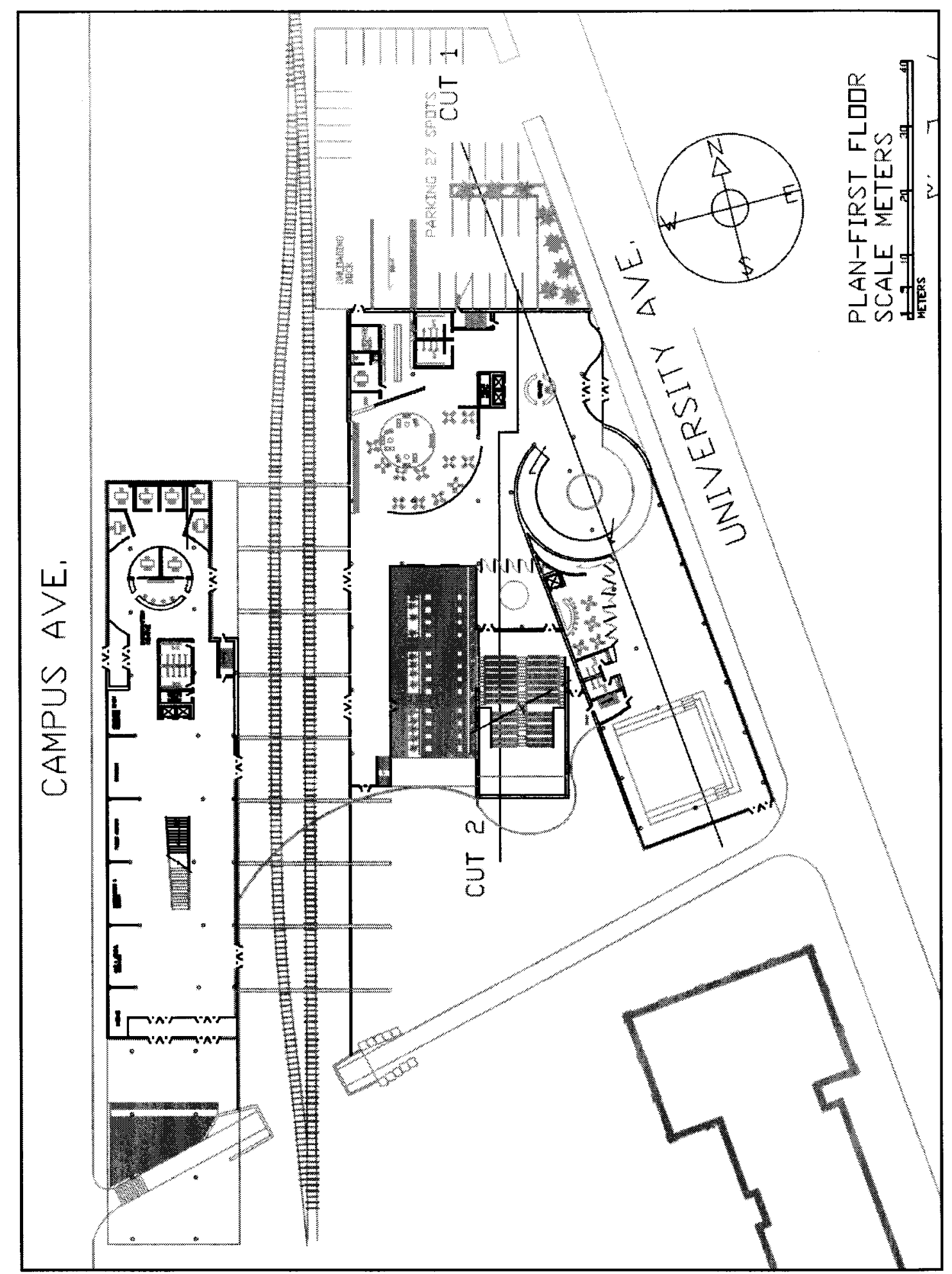

Figure 18: First Floor Plan

The first floor plan shows the open relationship of spaces for easy access of visitors to the building. The track becomes part of the building. 


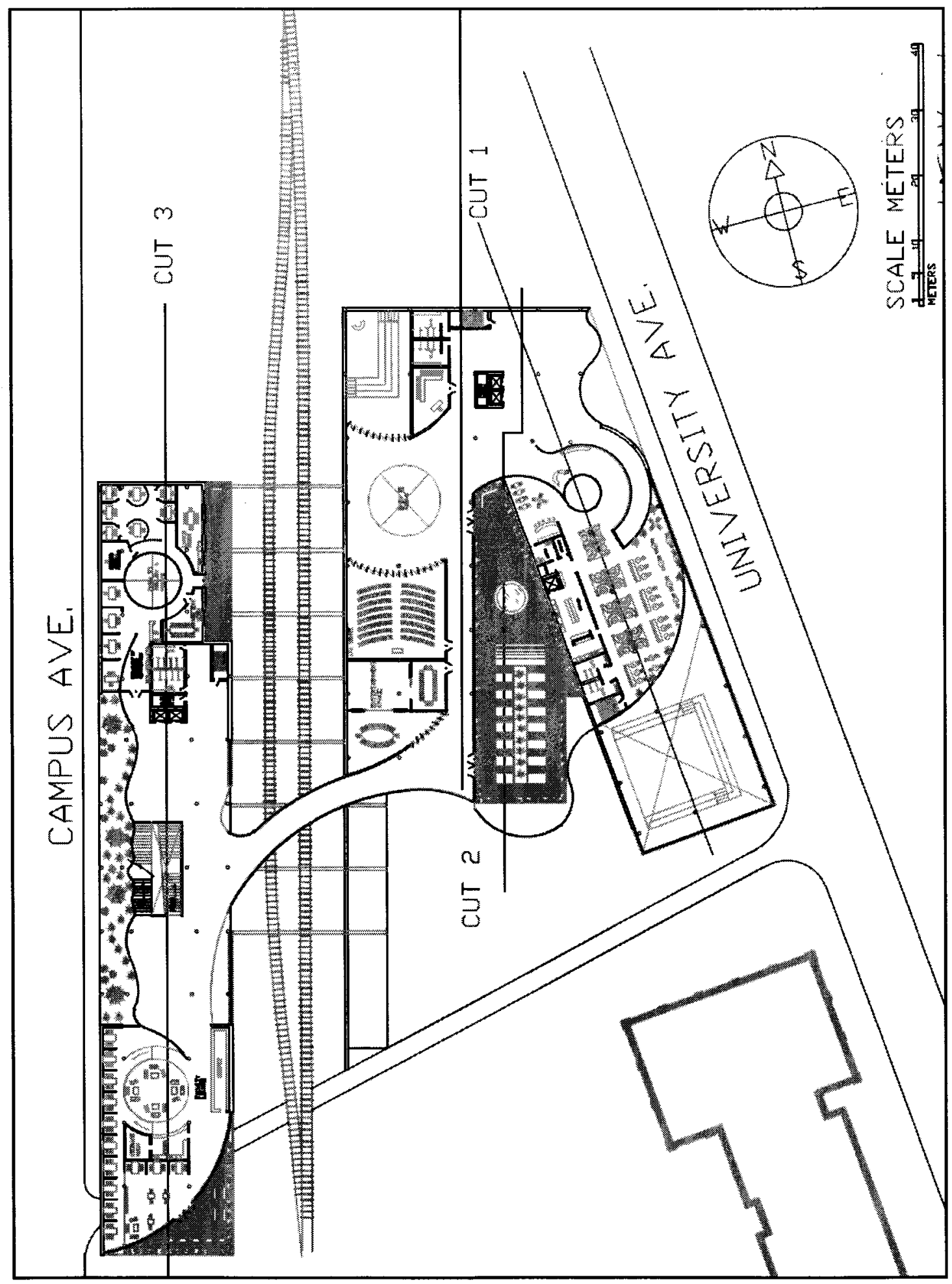

Figure 19: Second Floor Plan

The second floor plan shows the agorian relationship of spaces for easy access to discourse. It comprises mainly of classroom and meeting spaces. A restaurant is available for dinner after meetings or evenings out. 


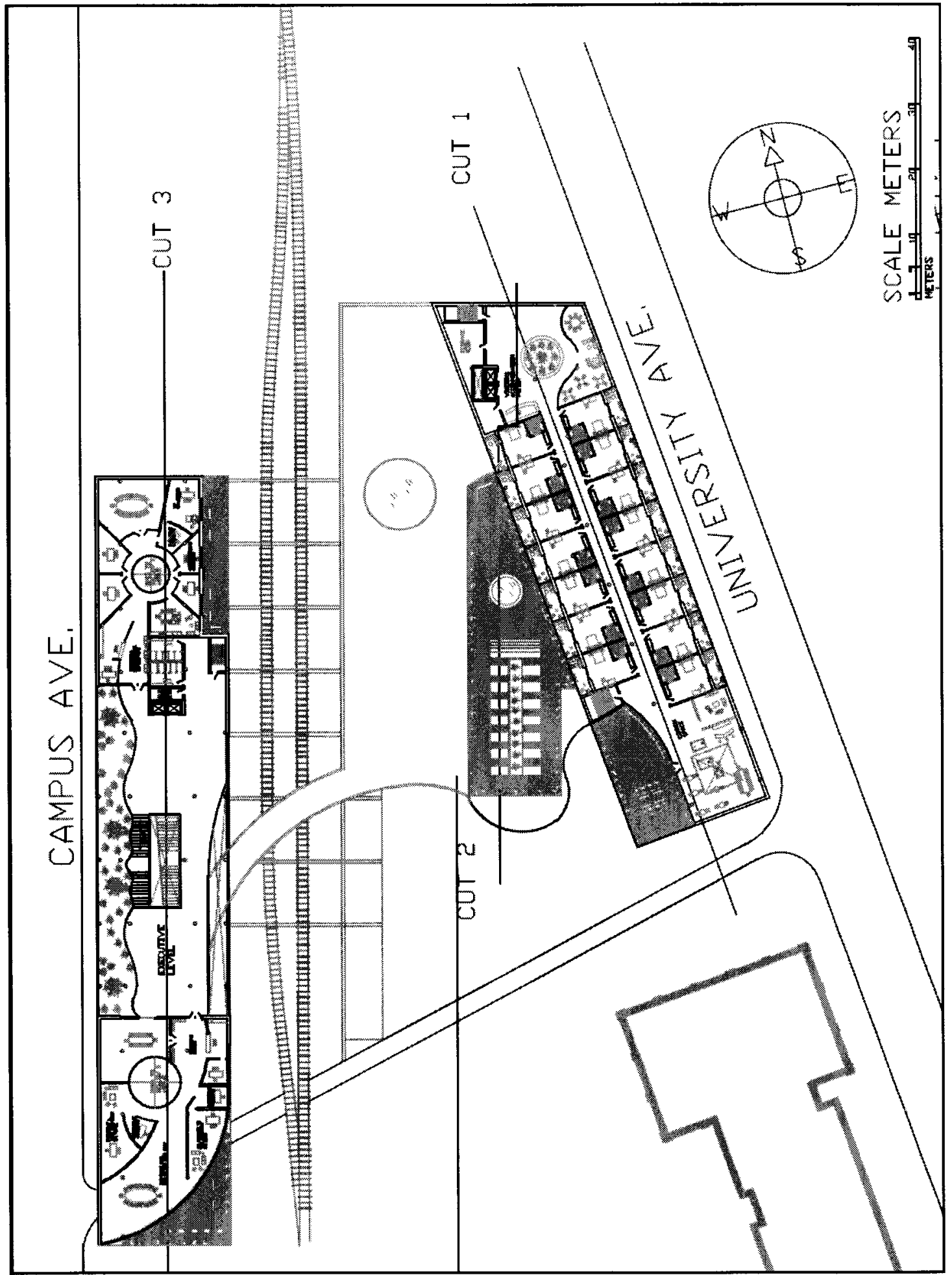

Figure 20: Third Floor Plan

The third floor plan becomes comprised of more private spaces. The offices of facilitators of the university are on the west side while the housing accommodations for visiting critics, professors and researchers are on the east side. 


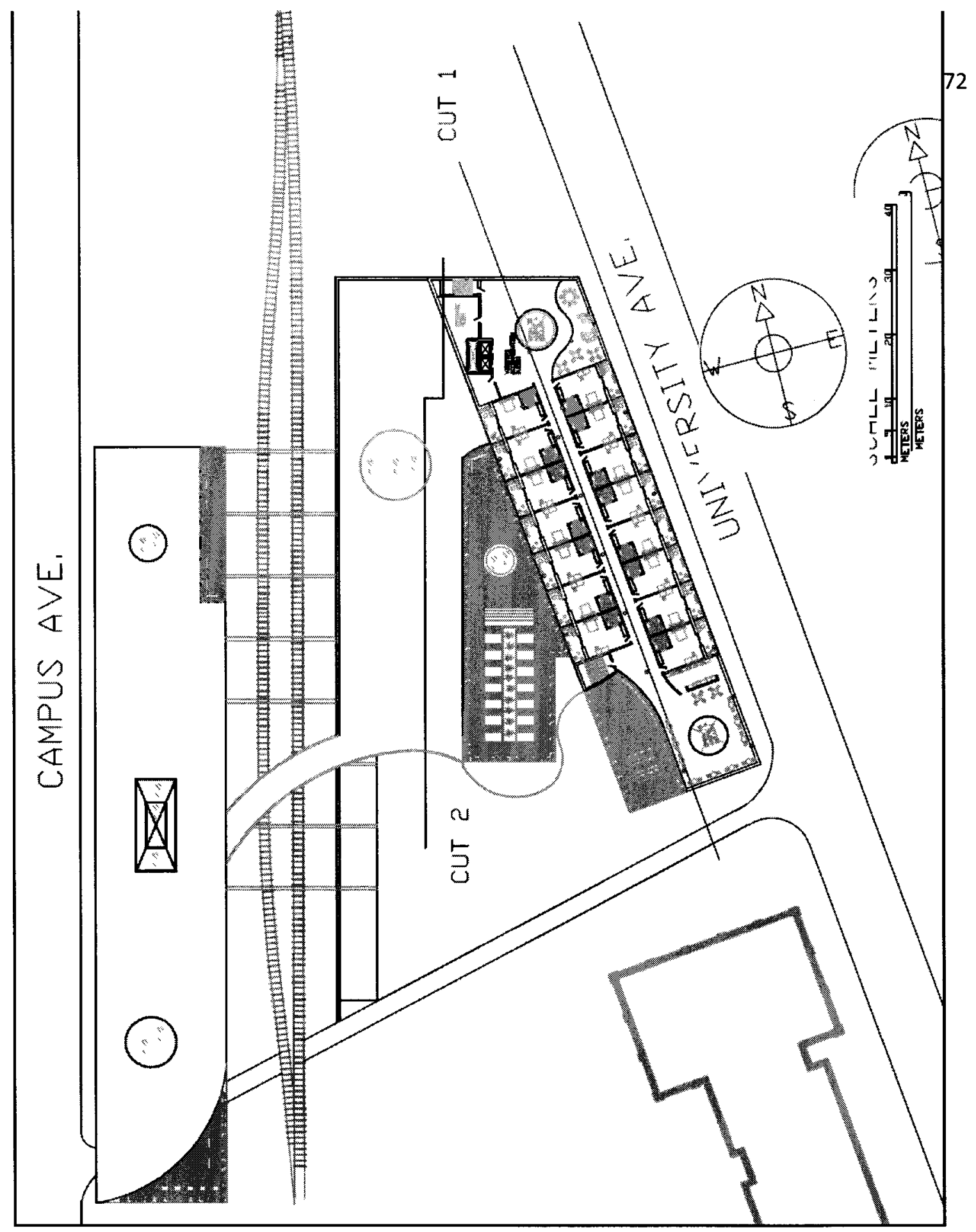

Figure 21: Fourth Floor Plan

The fourth floor plan becomes comprised of more private spaces. Housing accommodations for visiting critics, professors and researchers are on the east side. 


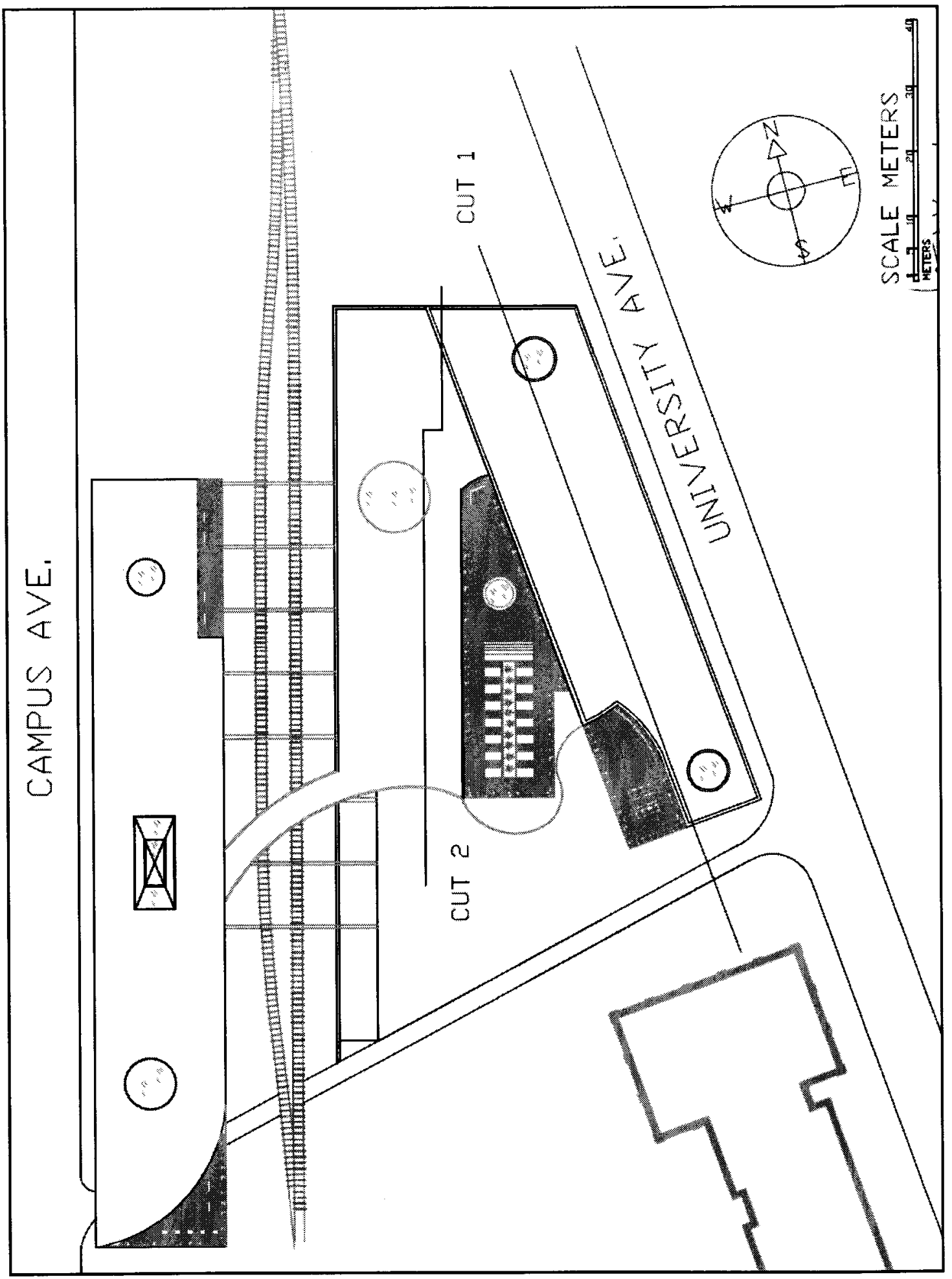

Figure 22: Roof Plan 


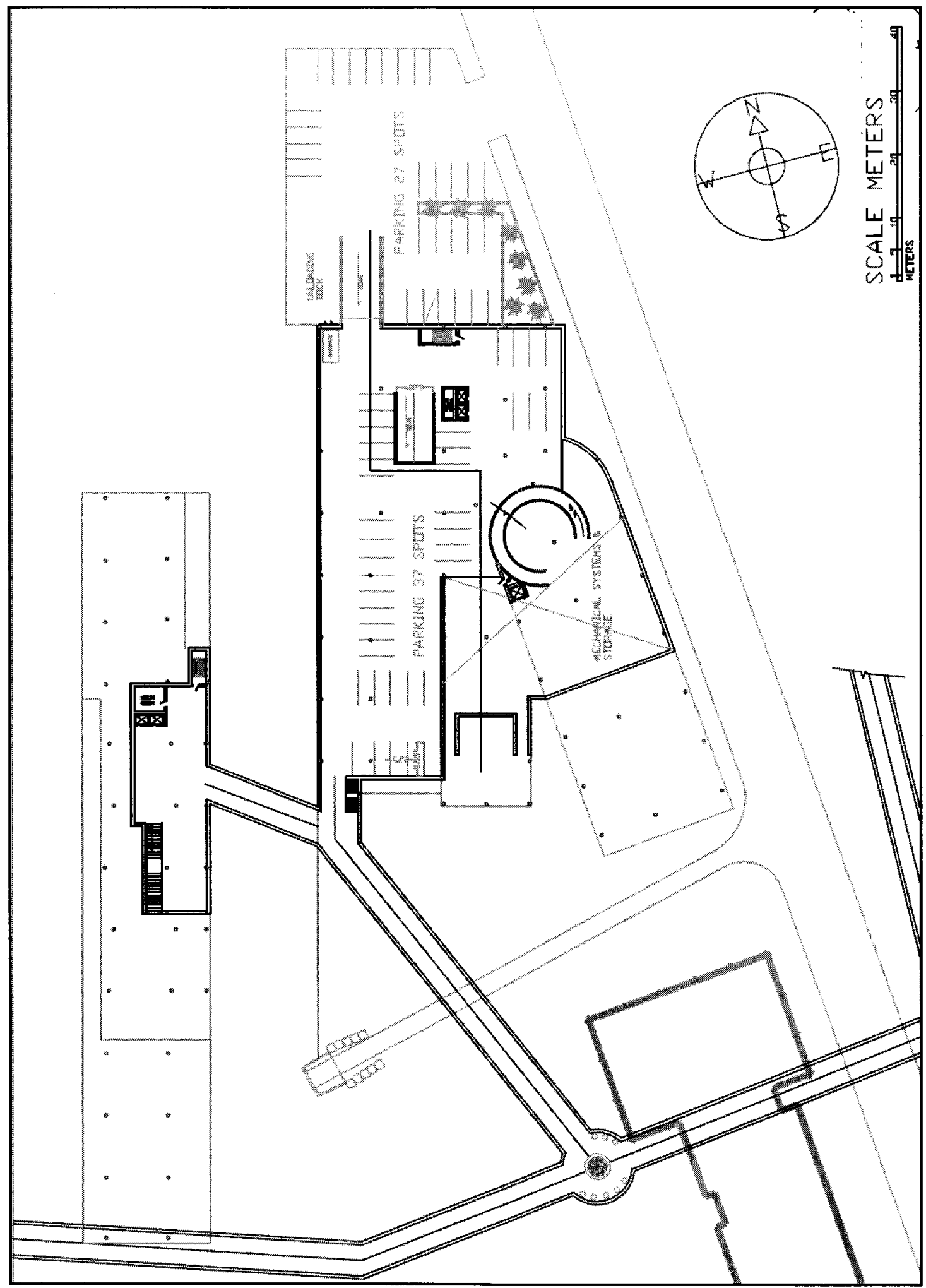

Figure 23: Basement and Tunnel Plan

The basement and tunnel floor plan shows the parking and storage facilities in the building. As well it also illustrates the connecting tunnel system. The subterranean tunnel at Carleton connects the buildings on site. 

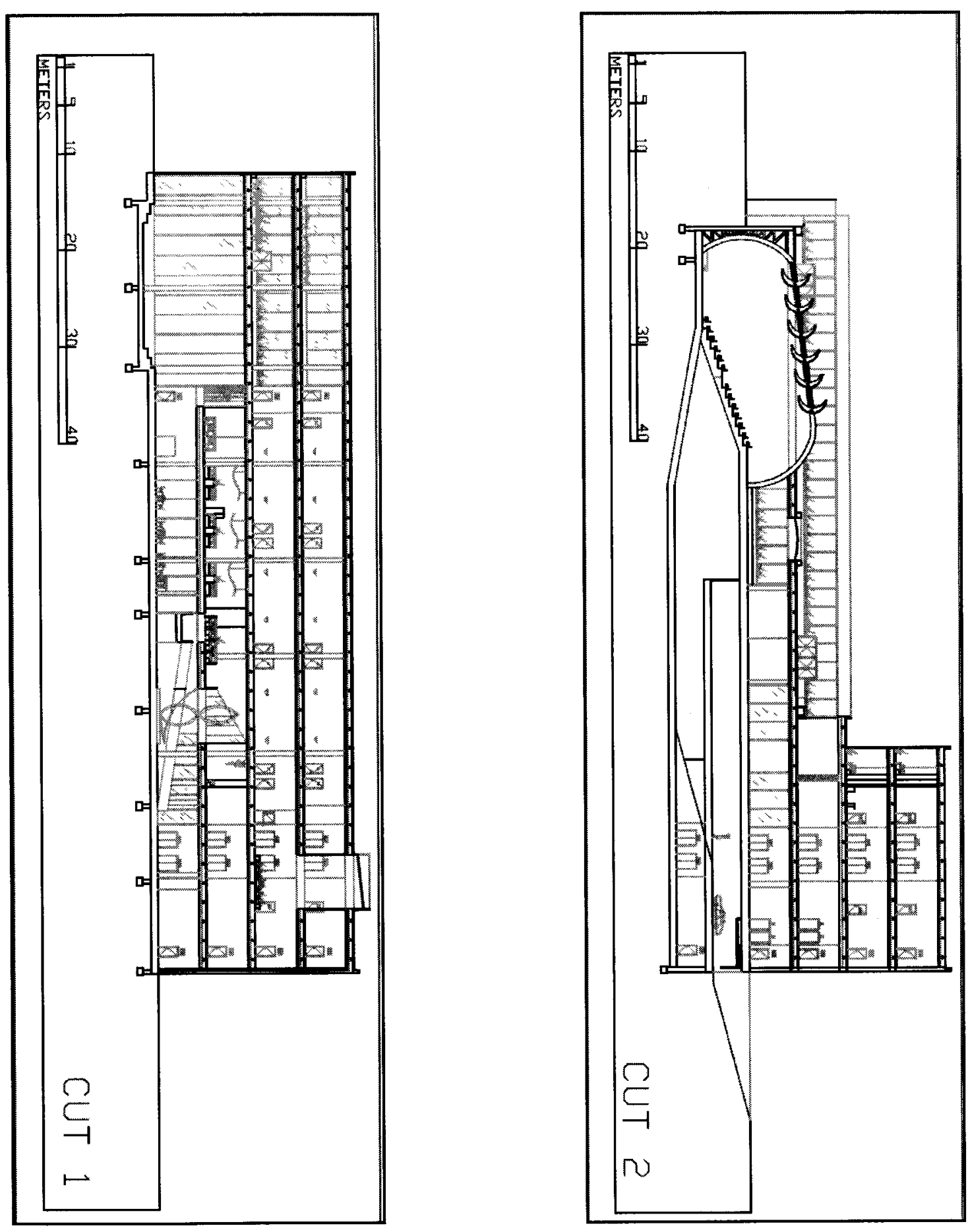

Figure 24: Sections

The left section cuts longitudinally through the main entrance, restaurant and gala space of the eastern building. The right section cuts longitudinally through the large auditorium and residences. 


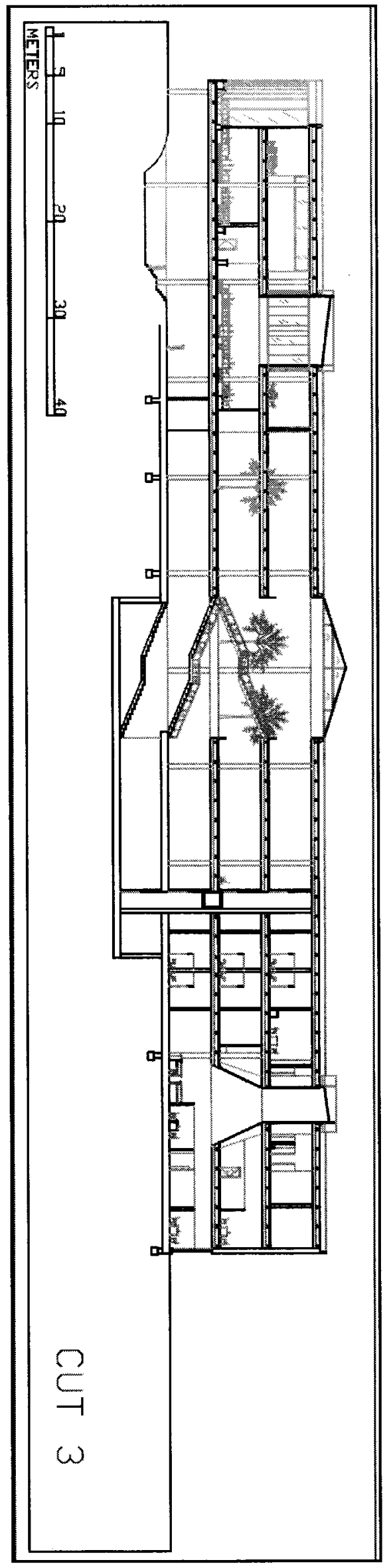

Figure 25: Section The section cuts longitudinally through the south entrance, gallery, faculty lounge and office spaces. 

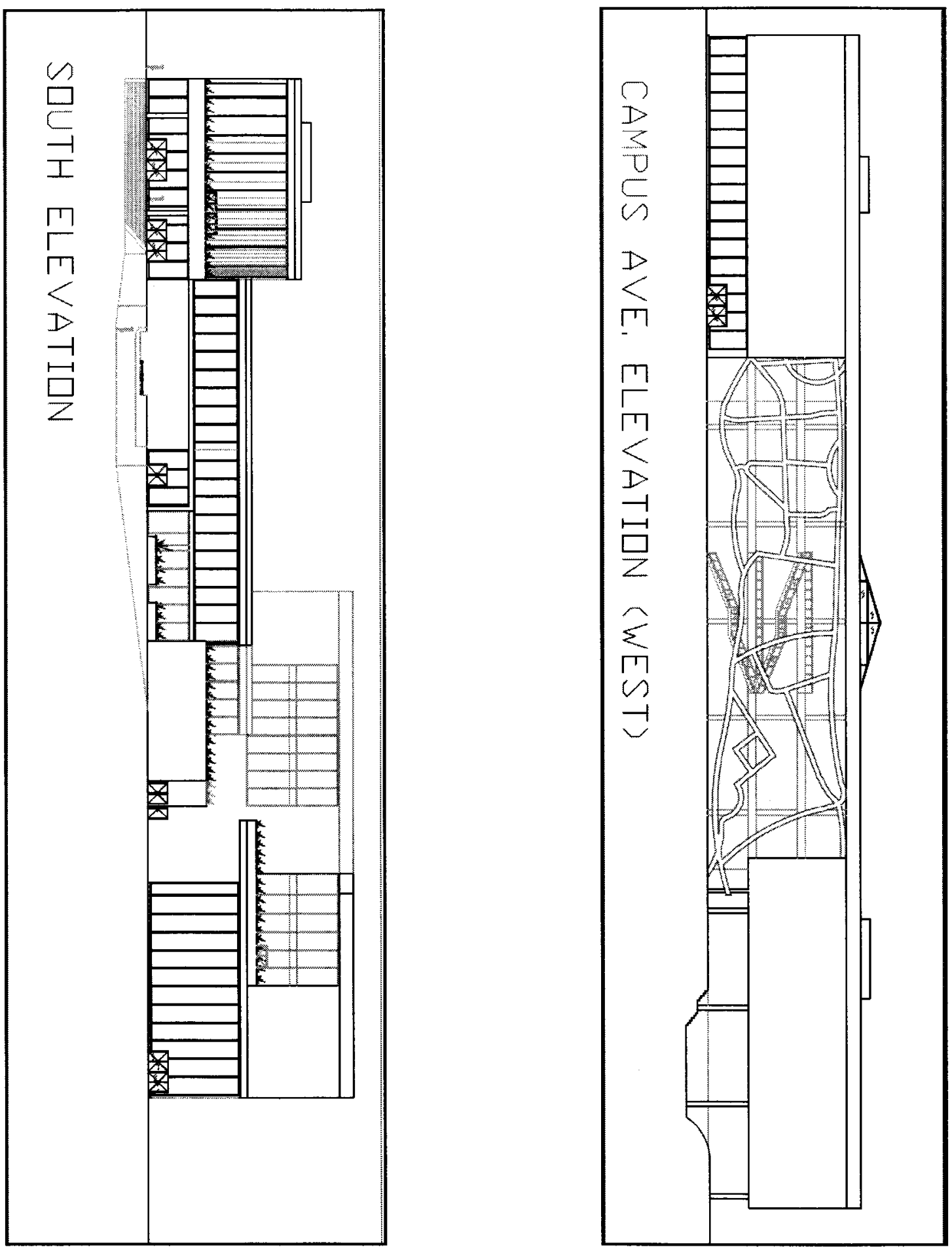

Figure 26: Elevations

The left elevation face south and has many gardens, which becomes important for sustainability as it reduces heat transference into the building. The right elevation is of the west. This elevation faces Campus Avenue, which is accessible to most of the academic buildings at the university as well as the main bus station. The front of the façade details LCD screens which takes surveillance images of specific spaces within the university and projects them onto the screens. 


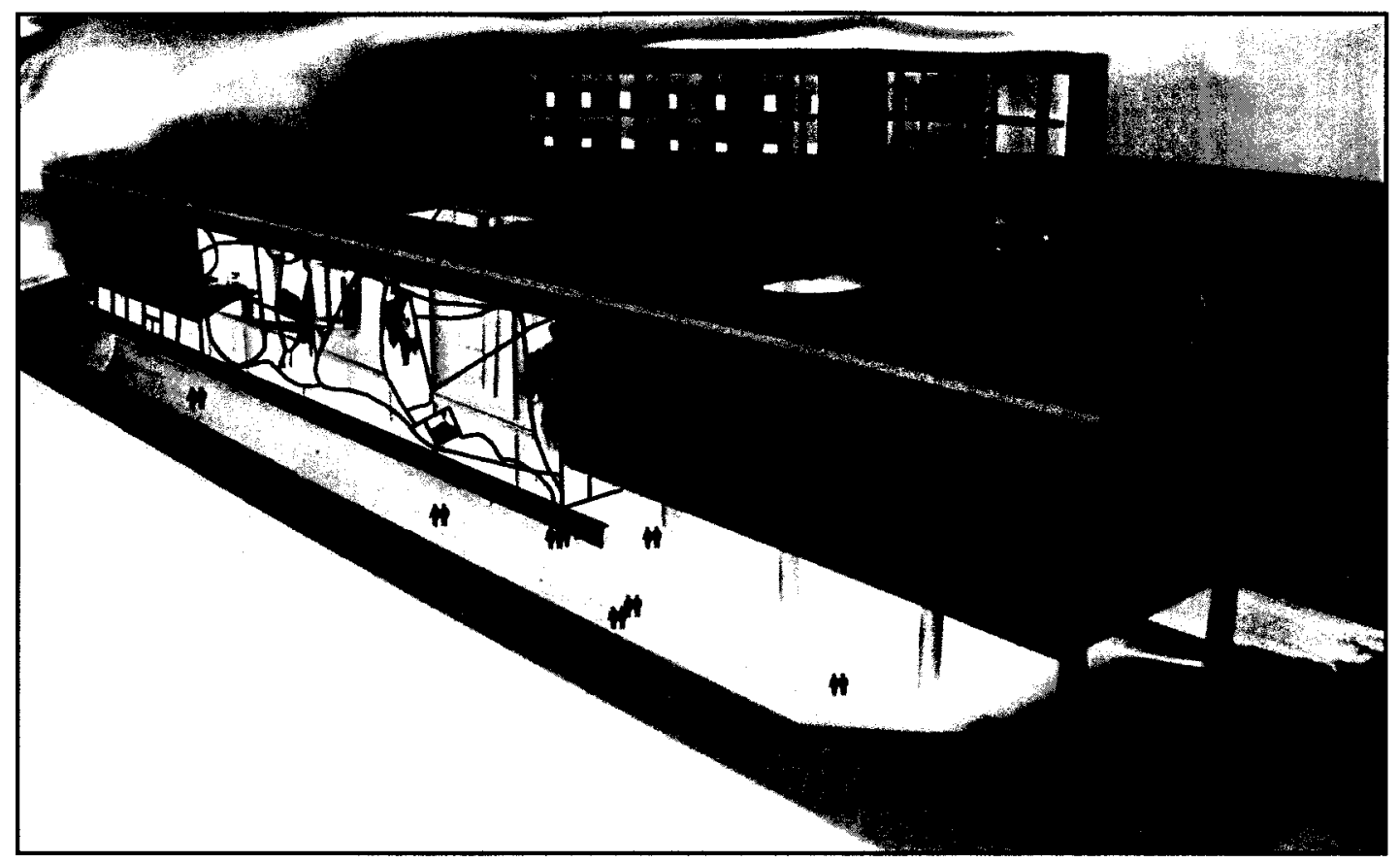

Figure 27 \& 28: Facade

Figure 27: The façade of the building interacts with surveillance cameras around the campus shown in figure 28. The images are illustrated on screens on the glazing. This creates a connection of the visitor to the site, and the movement within the facility.

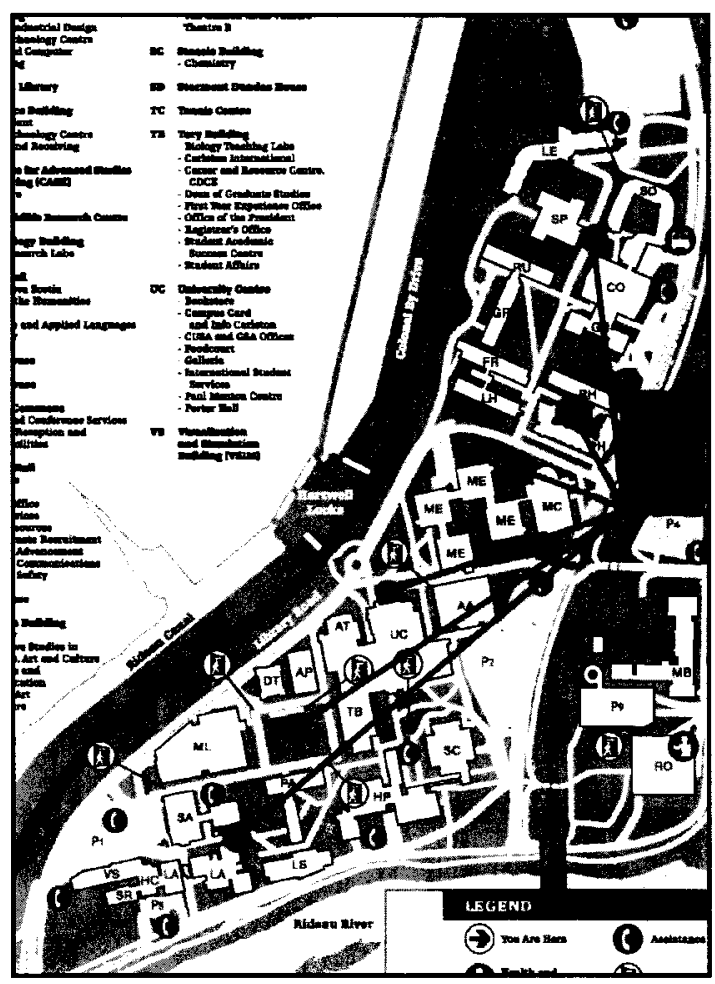




\section{Conclusion}

After examining Communication Technologies (CT) affiliation to the populace on a global, city and intimate scales, as well as Supermodernity, and how the internet causes the movement of vast amounts of information to flow readily, whether it be verifiable or not, a new paradigm is discovered: that the connection of the body to the way people move, interact and dwell within space is different from the interaction before CT became predominant. It seems a new global culture dependent upon the ease and accessibility of information is being brought to the forefront:

Dating to the invention of the telegraph-which enables people to communicate across great distances from different locales around the world- the advent of communication technologies has gone as far as one's imagination can extend. As millions of radio signals travel across the globe to their respective destinations each day, communication technologies have allowed us to share our experiences and cultures wherever these linkages exist. ${ }^{61}$

As the populace becomes fused within the network of quantitative dialogue, people become more dependent upon CT. The dependency on communication envelopes our beings in an information suit, gathering and outsourcing many bytes of electrical text making ourselves the initial movers of information. It is a networked culture, bound together by similar desires and aspirations for progress. As a result of this new paradigm shift, it has become apparent that people are directly affected by CT. People have been influenced to the extent that the public and private realms have merged, thus creating a fusion

61 Lin, 3. 
between work and home. It seems that $\mathrm{CT}$ has diluted individuality and made a global culture.

By exploring the way people are affected by CT and their social affiliation to place, memory and history, it is proposed that Architecture creates a narrative for the way human beings experience the world. Through the examination of the skin and its connection to site, as well as the way the functionalistic nature of information may be fused with the qualitative nature of our social institutions that encompass memory, history and culture, the author attempts to create the connection between $\mathrm{CT}$ and the social institution; CT influences Architecture. When Architecture is influenced by $\mathrm{CT}$, the spaces become a fluid environment. Movement in and out of in-betweenness creates a bond between physical place and the electrical through its agorian encounters and fluid spaces. The exterior façade of the Architecture, bound to site by the weather, wind, city bustle, surveillance videos, light or colours, offers direct affiliation with the narrative of the building. The skin provides the motivation for a person to become disconnected to his/her self for a moment, being aware of the influence that CT has in their lives and how people wear a new communication skin without being fully aware of it.

Architecture seems to bind purpose and function, as well as sensorial relationships bound with the dwellers that move throughout the spaces. As the populous becomes fused to $\mathrm{CT}$, and vice versa, the artifact (quantitative) and ritual (qualitative) that define Architecture should follow suit in order to maintain a successful dialogue with the human condition. 
After considering CT's impact on human beings and Architecture, a gateway to Carleton University was designed, illustrating the bond between CT and the social construct, and the way Architecture has become an important aspect of this change. The images of the surveillance videos from specific sections of the university are displayed on the façade of the building. This method attempts to offer a real time narrative of the university where visitors may become accustomed to the spaces on campus. The images propose a connection to memory for the visitors by introducing a visual aid for moving throughout the university before coming into contact with the spaces.

This study contributes to the understanding of the way CT has changed people's navigation within space, their interactions and their methods of business. This insight hopefully demonstrates how Architecture, as a mode of expression of humanity, must also change in accordance to the way society has progressed. The thesis attempts to make aware that social changes which occur on a personal level can snowball from a microcosmic to a macrocosmic level. Architecture is the narrative in which human beings can express this change as a whole, and visually be made aware of this social change as it occurs.

This study is an important attribute to the sociological changes that are occurring presently due to the mass application of $C T$ in our lives. We learn that even small alterations in the way we communicate can lead to larger changes in our social structuring.

A gateway to Carleton University using CT as a medium of expression will add value to the campus, as it further demonstrates the importance of research 
using $\mathrm{CT}$, and how the university not only reflects to the past for education, but turns to the future to impress upon the world new methods of research in a present application. The gateway conveys progressiveness and the merging between university and city. Now that a gateway to Carleton University has been conceived, could this become a trend for other institutions to use CT as a mode of communication in Architecture? 


\section{Glossary}

Place: Place embodies the connection to the inhabitant of the building through memory and history facilitated through the experiences and connection that the inhabitant has with place.

Artifact: Preludes a sense of quantitative approach to Architecture, through visual context, without understanding the merit of the space.

Ritual: Preludes a sense of qualitative approach through the actions and functions of the populous (memory and history) that inhabit a space, thus creating a narrative within Architecture.

Communication Technology: Is expressed as modes of transport by internet and cellular devices using electrical waves.

Information: Is the acquisition of written or verbal materials (be it tactile or electrical), through which knowledge and truth can be sought after.

Knowledge: This word suggests that the populous understands the information being received. Knowledge is the willingness to question information and extract truth.

Value: This word is used in direct opposition to the word Commodity. Value signifies the truth and falsehood of information; and whether or not truth is being questioned, and information is becoming excess.

Supermodernity: The overabundance and accessibility of information taken out of context from historical identity which causes an excess of meaningful events. "Supermodernity causes a number of excesses. Time moves so quickly that it is difficult to get one's bearings in history. Distance is so easily surmounted that one loses the sense that territoriality and space have any reality, and the individual becomes the point of reference for the distribution of information." Mark Augé

Qualifiable Space: Maintains its relationship to the environment, history and inhabitants.

Quantifiable Space: Exudes a sense of functionality and numerical diologue, for example, the bombardment of computer screens and bank machines.

Modernity: Modernity, used in sociological terms, looks to past events in history as a guideline on how to appropriate the future, in economics, politics and standards of living. Modernism improves the social surroundings by considering 
the past and not reinventing its mistakes: "Modernity is thus a particular kind of time consciousness which defines the present in its relation to the past, which must be consciously recreated....6?

Global Culture: The overabundance of information traveling around the globe through Internet, media and cellular activity, seems to be causing a generalized global culture. The outcome produced is a mass cultural identity, where many unique cultures become dissolved, being replaced by a common mind set.

Ethnocide: Ethnocide occurs when a more powerful culture imposes upon another its norms and practices.

Non-Place: Non-place begins to exude negative qualities of place, essentially the absence of place from itself. "If place can be defined as relational, historical and concerned with identity, then space which cannot be defined a relational, or historical, or concerned with identity will be a non-place. ${ }^{, 63}$

In-betweenness: Is the state of being in a transitory space, that of a threshold or gateway between one state and the next. A person or subject is caught between two extreme-contrasting conditions; the state of being caught between physical and electrical worlds.

Physical Space: Is the human body as it relates physically to its surroundings. Is the ability to converse within a physical relationship to another and to the site.

Electrical Space: Is the abitity to pass infinite amounts of information within a couple of seconds from pressing "send". It is the act of communication through electricity and airwaves, which removes our conversation out of physical space.

Haptic Senses: Are predominantly the sense of touch.

Skin: Is the mode in which Architecture expresses itself outwardly and collects information inwardly. The skin experiences the stimuli to the physical world.

Agora: Space comprises of walking and standing bodies, which permitted for fluid motion. The agora was not organized into distinct parts. It permitted the pedestrian to meander throughout the space, provoking conversation and confrontation.

Forum: Authoritative space used as a means of control, in order to direct information through dictatoriship to the audience.

\footnotetext{
${ }^{62}$ Delanty, 2007

${ }^{63}$ Ricoeur, 2004.
} 
The vulnerability of the viewer to the authority of the speaker was caused by the ability to control the movement and attention of the viewer. By placing the spectators in a sitting position, facing the stage (the spectacle), there was a less likely chance of the viewer encountering and divulging in converse with another person, such as happened in the agora. The pnyx was a beginning of the Roman Forum-were information was presented through the organization of bodies and thus thought. By controlling the movement of the people, information could more easily be presented. "Whereas the open-air life of the agora took place mostly among walking and standing bodies, the Pnyx made political use of such sitting, spectator bodies. They had to do the work of governing themselves, from a passive and vulnerable posture. In this posture they listened to the naked voice speaking below. "64

${ }^{64}$ Sennett,60-61. 


\section{Bibliography}

Augé, Marc. Non-Places: Introduction to an Anthropology of Supermodernity. New York: Verso, 1995.

Bernhard Schneider, Daniel Libeskind: Jewish Museum Berlin-Between The Lines. New York: Prestel Books, 2007

Casey, Edward. The Fate of Place: A Philosophical History. California: University of California Press, 1997.

De Kerckhove, Derrick. The Architecture of Intelligence. Berlin: Birkhauser, 2001

Flusser, Vilem. The Shape of Things: A Philosophy of Design. London: Reaktion Books, 1999.

Fry, Tony. Design Futuring - Sustainability, Ethics and New Practice. Berg Editorial Office, 2009.

Giuliana, Bruno. Public Intimacy, Architecture And the Visual Arts. Massachusetts: Massachusetts Institute of Technology, 2007.

Jacobs, Jane. Dark Age Ahead. Vintage Canada, 2005.

Jordidio, Philip. AE Architecture in the Emirates. Taschen, 2007.

Joseph Rykwert, The Seduction of Place: The City in the Twenty First Century. New York: Pantheon Books,2000.

Lynch, Kevin. The Image of the City. The MIT Press, 1960

Lynch, Kevin. A Theory of Good City Form. MIT Press, 1981

Moeller Christian, A Time And Place-Media Architecture. Switzerland: Lars Muller Publishers, 2004.

Pallasmaa, Juhani. The Eyes of The Skin: Architecture and the Senses. Great Britain: Wiley-Academy, 2005.

Postman, Neil. Technopoly: The Surrender of Culture to Technology. New York: Vintage Books, 1992.

Ricoeur, Paul. Memory, History, Forgetting. Chicago: The University of Chicago Press, 2004.

Rossi, Aldo. The Architecture of the City. Opposition Books, The Institute of Architecture and Urban Studies at M.I.T,1982. 
Rush, Fred. On Architecture: Thinking in Action. London: Routledge, 2009.

Sennett, Richard, Flesh and Stone: The body and the city in western Civilization. United States: Published as a Norton Paperback, 1996.

\section{Partial Excerpts}

Canizaro, Vincent B. Architectural Regionalism: Collected Writings on Place, Identity. Papress, 2007

Delanty,Gerard. Modernity" Blackwell Encyclopedia of Sociology, George Ritzer eds., Blackwell Publishing, 2007

Morgan, Conway Lloyd, Jean Nouvel: The elements of Architecture. Universe Publishing, 1998.

Noeleen Murray, Nick Shepherd and Martin Hall. Desire Lines Space, Memory and Identity in the Post Apartheid City. London: Routledge,2007.

\section{Internet Resources}

Brand, Shira, The Concise Oxford Dictionary, R.E. Allen, ed., Oxford University Press, 1991.

Colin B. Liddell ,"Toyo Ito interview: architecture week". Jan, 2007. www.architecturalinterviews.blogspot.com

Daniel Libeskind, Between The Lines.2010. www.daniel-libeskind.com

David Howes. "Architecture of The Senses". Sense of The City Exhibition Catalogue. Montreal, 2005. www.david-howes.com/DH-research-sampler-archsenses.htm

Jean Nouvel. "Torre Agbar"January 2, 2006.www.arcspace.com/architects.nouvel/agbar/agbar.html.

Mark Favermann, Berlins Jewish Museum By Daniel Libeskind: A Flawed Museum in a Deconstructionist Masterwork, (Berkshire Website Hosting),2009. www. berkshirefinearts.com/?page=article_id1112\&catlD $=26$

Miniwatts World Total internet Marketing Group, "US Census Bureau, Internet World Stats," www.newwebsitebuilders.net/Astounding\%internet\%20world\%stats\%20and\%20o nline\%20growth.\%20exposure.pdf. 
Pauline Tam, "Death of light rail forces Carleton to scrap \$70M showpiece," The Ottawa Citizen, December 12, 2007, http://forumskyscraperpage. com/showthread.php?t=140075\&page=21.

Toyo Ito, "Image of Architecture in electronic age". Designboom, 2010 www.designboom.com/eng.interview/ito_statement.html.

Toyo Ito, "Image of Architecture in electronic age". Designboom, 2010 www.designboom.com/eng.interview/ito_statement.html.

Defining Haptics: http://en.wikipedia.org/wiki/Haptics 